NASA

Technical Paper 1287
AVRADCOM

Technical Report 78-18

Effect of Geometry on Hydrodynamic Film Thickness

David E. Brewe; Bernard J. Hamrock, and Christopher M. Taylor 


\section{Effect of Geometry on}

\section{Hydrodynamic Film Thickness}

David E. Brewe

Propulsion Laboratory, AVRADCOM Research and Technology Laboratories Cleveland, Obio

Bernard J. Hamrock

Lewis Research Center

Cleveland, Obio

Christopher M. Taylor

University of Leeds

Leeds, England 


\section{SUMMARY}

The influence of geometry on the isothermal hydrodynamic film separating two rigid solids was investigated. The investigation was conducted for a conjunction fully im mersed in lubricant (i. e., fully flooded). The effect of geometry on the film thickness was determined by varying the radius ratio from 1 (a ball-on-plate configuration) to 36 (a ball in a conforming groove). The dimensionless film thickness was varied from $10^{-5}$ to $10^{-4}$. Pressure-viscosity effects were not considered. It was found that the minimum film thickness had the same speed, viscosity, and load dependence as Kapitza's classical solution. However, the incorporation of the Reynolds boundary conditions resulted in an additional geometry effect. That is, the film-thickness equations can be compared as follows:

$$
\begin{aligned}
& \left.\mathrm{H}_{0}=128 \alpha\left[\epsilon\left(\mathrm{H}_{0}\right) \frac{\varphi \mathrm{U}}{\mathrm{W}} \quad 0.131 \tan ^{-1} \frac{\alpha}{2}+1.683\right)\right]^{2} \quad\left\{\begin{array}{l}
\text { Full circular film; } \\
\text { Reynolds boundary conditions }
\end{array}\right. \\
& \mathrm{H}_{0}=128 \alpha\left[\frac{\varphi \mathrm{U}}{\mathrm{W}}\left(0.131 \tan ^{-1} \frac{\alpha}{2}+1.683\right)\right]^{2} \quad\left\{\begin{array}{l}
\text { Parabolic approximation; } \\
\text { Reynolds boundary conditions }
\end{array}\right. \\
& \mathrm{H}_{0}=128 \alpha\left(\frac{\varphi \mathrm{U}}{\mathrm{W}} \frac{\pi}{2}\right)^{2} \quad\left\{\begin{array}{l}
\text { Parabolic approximation; } \\
\text { half-Sommerfeld boundary } \\
\text { conditions }
\end{array}\right.
\end{aligned}
$$

where $\mathrm{H}_{0}$ is the dimensionless central (minimum) film thickness, $\alpha$ is the radius ratio $R_{y} / R_{x}, \epsilon$ is the film-thickness effect on reduced hydrodynamic lift, and $U / W$ is the ratio of dimensionless speed to dimensionless load. With the Reynolds boundary conditions the predicted load capacity is 11 to 20 percent greater than if halfSommerfeld boundary conditions are used. The parabolic approximation results in overestimations of the minimum film thickness of 1.6 and 0.7 percent for dimensionless minimum film thicknesses of $10^{-4}$ and $10^{-5}$, respectively. 


\section{INTRODUCTION}

A considerable amount of work (refs. 1 to 6 ) has been done to develop a minimum film-thickness formula for the classical hydrodynamic point-and line-contact problems. Most of the work to date has concentrated on minimum-film-thickness formulations for either a ball on a plate or line contact. But the full range of geometries between the two extremes has not been adequately studied. Kapitza's film -thickness solution (ref. 1) is not limited to a ball-on-plate configuration. However, applying the half-Sommerfeld boundary conditions used in Kapitza's analysis violates flow continuity at the cavitation boundary. Consequently, a need exists for a film-thickness formula that is determined by more realistic boundary conditions and that applies for a wide range of geometries.

Work (refs. 7 to 10 ) has been presented in which the minimum film thickness was determined by using an elastohydrodynamic lubrication (EHL) point-contact theory. There the influence of contact geometry - as expressed by the ellipticity parameter and the effects of the dimensionless speed, load, and material parameters on the minimum film thickness - was investigated for both the fully flooded and starved conditions. This paper continués the previous work to form a more complete theory. However, to properly bring out the physics requires a modification to the analytical approach used in the previous work. Here the effect of load capacity has been studied by varying the ratio of the transverse radius to the rolling radius ("radius ratio") for two film thicknesses. The investigation was conducted for a conjunction fully immersed in lubricant (i.e., fully flooded). The radius ratio was varied from 1 (a ball-on-plate configuration) to 36 (a ball in a conforming groove). The dimensionless film thickness was varied from $10^{-5}$ to $10^{-4}$. Thirteen cases were used in obtaining the film-thickness formula, for which pressure and thermal effects were considered to be negligible. Contour and profile plots of the pressure distribution are also shown.

\section{SYMBOLS}

$a_{0}, a_{1}$ least-squares coefficients

D difference, $\left[\left(\tilde{\mathrm{H}}_{\min }-\mathrm{H}_{\mathrm{min}}\right) / \mathrm{H}_{\min }\right] \times 100$, percent

G material parameter

$\mathrm{H}$ dimensionless film thickness, $\mathrm{h} / \mathrm{R}_{\mathrm{x}}$

$\mathrm{H}_{0}$ dimensionless central (minimum) film thickness, $h_{0} / R_{x}$.

$\tilde{\mathrm{H}}_{0} \quad$ calculated dimensionless central (minimum) film thickness from least-squares analysis

h film thickness, cm 
$h_{0}$ central (minimum) film thickness, cm

L reduced hydrodynamic lift

m starvation parameter (percent loss in load capacity)

$N \quad$ direction normal to boundary

$P$ dimensionless pressure, $\mathrm{pR}_{\mathrm{X}} / \nu_{0}^{\mathrm{u}}$

p pressure, $\mathrm{N} / \mathrm{cm}^{2}$

Q solution to homogeneous Reynolds equation

$\mathrm{R}$ effective radius of curvature, $\mathrm{cm}$

$r$ radius of curvature, $\mathrm{cm}$

$\mathrm{S} \quad$ separation due to geometry of solids, $\mathrm{cm}$

$\mathrm{U} / \mathrm{W}$ ratio of dimensionless speed to dimensionless load

$u$ average surface velocity in $x$-direction $\left(u_{A}+u_{B}\right) / 2, c m / s e c$

w load capacity, $\mathrm{N}$

$\mathrm{X}$ dimensionless coordinate, $\mathrm{x} / \mathrm{R}_{\mathrm{X}}$

$\mathrm{X}$ coordinate along rolling direction, $\mathrm{cm}$

$Y$ dimensionless coordinate, $y / R_{x}$

y coordinate transverse to rolling direction, $\mathrm{cm}$

$\alpha$ radius ratio, $\mathrm{R}_{\mathrm{y}} / \mathrm{R}_{\mathrm{x}}$

$\epsilon \quad$ film-thickness effect on reduced hydrodynamic lift

$\eta \quad$ dimensionless coordinate, $\mathrm{Y} / \sqrt{2 \alpha \mathrm{H}_{0}}$

$\nu_{0} \quad$ fluid viscosity at standard temperature and pressure, $\mathrm{N} \cdot \mathrm{sec} / \mathrm{cm}^{2}$

$\varphi \quad$ Archard-Cowking side-leakage factor, $[1+(2 / 3 \alpha)]^{-1}$

$X$ dimensionless coordinate, $X / \sqrt{2 \mathrm{H}_{0}}$

Subscripts:
A solid A
B solid B
E entrance, or inlet
$\mathrm{x}, \mathrm{y}$ coordinate direction
0 center of contact
$\infty \quad$ infinite domain 


\section{THEORETICAL FORMULATION}

\section{Solution for Central Film Thickness}

The thickness of a hydrodynamic film between two rigid bodies in rolling contact can be written as the sum of two terms; that is,

$$
h=h_{0}+S(x, y)
$$

where

$h_{0} \quad$ central (also minimum) film thickness due to hydrodynamic effects

$\mathrm{S}(\mathrm{x}, \mathrm{y})$ separation due to geometry of solids

The separation of two rigid solids (fig. 1(a)) in which the principal axes of inertia of the two bodies are parallel can be written as

$$
\mathrm{S}=\mathrm{S}_{\mathrm{Ax}}+\mathrm{S}_{\mathrm{Bx}}+\mathrm{S}_{\mathrm{Ay}}+\mathrm{S}_{\mathrm{By}}
$$

where

$$
\begin{aligned}
& S_{A x}=r_{A x}-\sqrt{r_{A x}^{2}-x^{2}} \\
& S_{B x}=r_{B x}-\sqrt{r_{B x}^{2}-x^{2}} \\
& S_{A y}=r_{A y}-\sqrt{r_{A y}^{2}-y^{2}} \\
& S_{B y}=r_{B y}-\sqrt{r_{B y}^{2}-y^{2}}
\end{aligned}
$$

A simplifying transformation can be effected by summing the curvatures in the $x=0$ and $y=0$ planes. In terms of the effective radius of curvature,

$$
\begin{aligned}
& \frac{1}{R_{x}}=\frac{1}{r_{A x}}+\frac{1}{r_{B x}} \\
& \frac{1}{R_{y}}=\frac{1}{r_{A y}}+\frac{1}{r_{B y}}
\end{aligned}
$$


The resulting equivalent system is shown in figure 1(b). The separation in terms of the coordinates and the effective radius of curvature is

$$
S(x, y)=R_{x}-\sqrt{R_{x}^{2}-x^{2}}+R_{y}-\sqrt{R_{y}^{2}-y^{2}}
$$

Thus equation (1) is completely determined when the hydrodynamic effects on the central film thickness are known. These effects can be determined by applying the conservation equations for an incompressible Newtonian fluid under laminar, isothermal, isoviscous, steady-state conditions. The following Reynolds equation is obtained:

$$
\frac{\partial}{\partial x}\left(h^{3} \frac{\partial p}{\partial x}\right)+\frac{\partial}{\partial y}\left(h^{3} \frac{\partial p}{\partial y}\right)=12 \nu_{0} u \frac{\partial h}{\partial x}
$$

where $u$ represents the average surface velocity between the two solids along the rolling direction. It is convenient to nondimensionalize with respect to the effective rolling radius; that is,

$$
X \equiv \frac{x}{R_{X}} \quad Y \equiv \frac{y}{R_{X}} \quad H \equiv \frac{h}{R_{X}}
$$

also

$$
\mathrm{P}=\frac{\mathrm{pR} \mathrm{x}}{\nu_{0} \mathrm{u}} \quad \alpha=\frac{\mathrm{R}_{\mathrm{y}}}{\mathrm{R}_{\mathrm{x}}}
$$

where $\alpha$ denotes the "radius ratio." In terms of these dimensionless variables the Reynolds equation becomes

$$
\frac{\partial}{\partial X}\left(H^{3} \frac{\partial P}{\partial X}\right)+\frac{\partial}{\partial Y}\left(H^{3} \frac{\partial P}{\partial Y}\right)=12 \frac{\partial H}{\partial X}
$$

The film-thickness equation in dimensionless form is

$$
\mathrm{H}=\mathrm{H}_{0}+1-\sqrt{1-\mathrm{X}^{2}}+\alpha\left(1-\sqrt{1-\frac{\mathrm{Y}^{2}}{\alpha^{2}}}\right)
$$

For situations in which $\mathrm{X}^{2}<<1$, and $(\mathrm{Y} / \alpha)^{2}<<1$, it is convenient to expand $\mathrm{H}$ in a two-dimensional Taylor series to give 


$$
\mathrm{H} \simeq \mathrm{H}_{0}+\frac{\mathrm{X}^{2}}{2}+\frac{\mathrm{Y}^{2}}{2 \alpha}
$$

This is called the parabolic approximation. The analysis to follow uses both forms of $\mathrm{H}$, and comparisons are made.

The solution of the Reynolds equation (eq. (5)) is known to consist of a homogeneous solution and a particular solution; that is,

$$
P=P_{p}+P_{h}
$$

for which $P_{h}$ is a solution to the homogeneous equation and satisfies the condition that $P_{h}=-P_{p}$ at the boundaries:

$$
\frac{\partial}{\partial X}\left(H^{3} \frac{\partial P_{h}}{\partial X}\right)+\frac{\partial}{\partial Y}\left(H^{3} \frac{\partial P_{h}}{\partial Y}\right)=0
$$

For the parabolic approximation, the particular solution for the pressure is simply proportional to $\mathrm{X} / \mathrm{H}^{2}$; that is,

$$
P_{p}=\frac{-4 \varphi X}{H^{2}}
$$

where

$$
\varphi=\frac{1}{\left(1+\frac{2}{3 \alpha}\right)}
$$

In the preceding equation $\varphi$ is the side-leakage factor established by Archard and Cowking (ref. 11) and can be verified by inserting $P_{p}$ back into equation (5). If we define $\mathrm{P}_{\mathrm{h}}(\mathrm{X}, \mathrm{Y})=4 \varphi \mathrm{Q}(\mathrm{X}, \mathrm{Y})$, by using equation (8), we can express the full solution as

$$
\mathrm{P}=4 \varphi\left(\frac{-\mathrm{X}}{\mathrm{H}^{2}}+\mathrm{Q}\right)
$$

In general, the homogeneous solution $\mathrm{P}_{\mathrm{h}}$ is an unknown function of $\mathrm{X}$ and $\mathrm{Y}$. Consequently, the pressure distribution must be determined numerically. The pressure dis tribution as given in equation (10) can be used, however, in relating the hydrodynamic effects (i. e., load, speed, and viscosity) to the central film thickness. First, the load capacity and the pressure distribution are related through the following equation: 


$$
w=\iint p d x d y
$$

or in dimensionless form (using eq. (4))

$$
\mathrm{w}=\nu_{0} \mathrm{uR} x \iint \mathrm{P} d \mathrm{X} d \mathrm{Y}
$$

Substituting equation (10) into this expression gives

$$
\mathrm{w}=4 v_{0} \mathrm{uR}_{\mathrm{X}} \varphi \iint\left(\frac{-\mathrm{X}}{\mathrm{H}^{2}}+\mathrm{Q}\right) \mathrm{dX} \mathrm{dY}
$$

For the parabolic film assumption, the central film thickness can be isolated from the integrand by defining the following transformation:

$$
\begin{gathered}
\mathrm{X}=\sqrt{2 \mathrm{H}_{0}} \mathrm{X} \\
\mathrm{Y}=\sqrt{2 \alpha \mathrm{H}_{0}} \eta
\end{gathered}
$$

If we assume the homogeneous solution to transform in the same manner as the particular solution, we obtain

$$
\mathrm{w}=8 \varphi \nu_{0} \mathrm{uR} x \sqrt{\frac{2 \alpha}{\mathrm{H}_{0}}} \iint\left[\frac{-\mathrm{x}}{\left(1+\mathrm{x}^{2}+\eta^{2}\right)^{2}}+\mathrm{Q}(\mathrm{x}, \eta)\right] \mathrm{dx} \mathrm{d} \eta
$$

Kapitza refers to this integral as the reduced hydrodynamic lift $L$. Thus,

$$
\mathrm{L} \equiv \iint\left[\frac{-\mathrm{x}}{\left(1+\mathrm{x}^{2}+\eta^{2}\right)^{2}}+\mathrm{Q}(\mathrm{x}, \eta)\right] \mathrm{d} \mathrm{x} \mathrm{d} \eta
$$

The reduced hydrodynamic lift in Kapitza's analysis was determined to be $\pi / 2$ by assuming $Q=0$ and integrating over the half-space of positive pressures. For Reynolds boundary conditions, the limits depend on the shape of the cavitation boundary and hence the geometry. Consequently, we seek an additional geometry effect in Kapitza's solution. Equation (12) enables us to determine the central (minimum) film thickness as a function of the load, speed, geometry, and fluid viscosity; that is, 


$$
H_{\min }=H_{0}=128 \alpha\left(\frac{\varphi \nu_{0} \mathrm{uR}_{\mathrm{x}}}{w}\right)^{2}
$$

The ratio of dimensionless speed to dimensionless load may be defined as

$$
\frac{\mathrm{U}}{\mathrm{W}}=\frac{\nu_{0} \mathrm{uR}_{\mathrm{x}}}{\mathrm{w}}
$$

and equation (14) becomes

$$
\mathrm{H}_{0}=128 \alpha\left(\frac{\varphi \mathrm{UL}}{\mathrm{W}}\right)^{2}
$$

For the parabolic approximation, we need to determine $\mathrm{L}$ only as a function of the geometry; that is,

$$
\mathrm{L}=\mathrm{L}(\alpha) \quad \text { if }\left\{\begin{array}{l}
\mathrm{x}^{2}<\left(1 / 2 \mathrm{H}_{0}\right) \\
\eta^{2}<\left(1 / 2 \mathrm{H}_{0}\right)
\end{array}\right.
$$

This will be determined numerically. If, on the other hand, the film thickness is large enough that these inequalities cannot be satisfied throughout most of the domain, the exact film -thickness equation (eq. (6)) must be used. The integrand of equation (13) thus becomes a function of the central film thickness. Consequently, $\mathrm{L}=\mathrm{L}\left(\alpha, \mathrm{H}_{0}\right)$, resulting in a transcendental equation for $\mathrm{H}_{0}$.

\section{Boundary Conditions}

Earlier theories (ref. 12) assumed the pressure to be ambient or zero at the point of closest approach. This resulted in an antisymmetric solution with respect to $X$ (fig. 2(a)). In actuality, the lubricant is unable to sustain the negative pressures predicted by the full solution. A simple approach taken by Kapitza (ref. 1) was to ignore the negative pressures, that is, to employ the half-Sommerfeld boundary conditions. This solution (fig. 2(b)) has been used to get a reasonable estimate for the load capacity. However, Kapitza's solution does not satisfy continuity conditions at the exit (cavitation) boundary; that is, the pressure gradient normal to the cavitation boundary must be zero. To insist on $P=(\partial P / \partial N)=0$ at $X=0$ would be overspecifying the problem mathematically. However, we can insist on $P=(\partial P / \partial N)=0$ at the cavitation boundary 
(i. e., Reynolds boundary conditions). The general solution will then appear as in figure 2(c). For film thicknesses of about $10^{-2}$ to $10^{-3}$ centimeter, Dowson (ref. 13) has shown that other boundary requirements are needed. For that investigation, the cavitation boundary as determined by the Reynolds boundary conditions did not coincide with the cavitation boundary observed experimentally. Taylor (ref. 14) has summarized several of the boundary requirements that have evolved as a result of Dowson's work. Among the boundary requirements discussed, the Reynolds boundary conditions were chosen as the most appropriate for the conditions of load and speed in this investigation.

\section{NUMERICAL ANALYSIS}

A pressure distribution satisfying the Reynolds equation (eq. (3)) was determined numerically for a given speed, viscosity, geometry, and film thickness. The numerical solution was achieved by using the Gauss-Seidel iterative method with overrelaxation. The parameter $\Phi=\mathrm{PH}^{3 / 2}$ (ref. 15) was introduced to help the relaxation process. A computer program is given in the appendix.

\section{Nodal Structure}

A variable-mesh nodal structure (fig. 3) was used to provide close spacing in and around the pressure peak. This helped to minimize the errors that can occur because of large gradients in the high-pressure region. The grid spacing used in terms of the co-ordinates $\mathrm{X}$ and $\mathrm{Y}$ was varied depending on anticipated pressure distribution. That is, for a very highly peaked and localized pressure distribution, the fine mesh spacing was about 0.002 and the coarse mesh spacing was about 0.1 . For a relatively flat pressure distribution, the fine mesh spacing was about 0.005 and the coarse mesh spacing was about 0.13 .

\section{Integration Domain}

The size of the conjunction, or the integration domain, is determined so as to make the contact fully flooded or as close to that as practical. From Dalmaz (ref. 3), a fully flooded condition for a ball -on-plate configuration would have an inlet domain defined by $X_{E}=-1$ and $Y_{E}= \pm 1$. By using the pressures from Kapitza's classical theory, the loss of load capacity resulting from using a finite inlet rather than the semi-infinite inlet used by Kapitza can be estimated. For this purpose let $\mathrm{m}$ represent the percent loss in load capacity; that is, 


$$
\mathrm{m}=\left(1-\frac{\mathrm{w}}{\mathrm{w}_{\infty}}\right) 100
$$

Thus as $\mathrm{m}$ approaches 100 , the inlet becomes severely starved. If $\mathrm{m}$ approaches zero, the inlet is considered fully flooded. For the ball-on-plate inlet domain, $\mathrm{m}$ is calculated to be 1.61 percent. Since this represents a negligible loss in load capacity, we chose to retain the concept that a fully flooded condition exists in this case. Henceforth, if $\mathrm{m} \leq 1.61$ percent, the inlet is considered as fully flooded. According to this criterion, the inlets for all the geometries considered in this investigation were fully flooded (table I). The exit boundary was determined so as to allow for a fully developed cavitation boundary.

In our effort to achieve a fully flooded condition, we recognize the fact that the Reynolds equation loses some of its validity at large distances from the point of minimum film thickness. Dowson (ref. 16) has pointed out that the errors involved in using this equation to determine the buildup of pressure in such regions are negligible: The predicted pressures are themselves so very much smaller than the effective load-carrying pressures in the region of closest approach of the solids.

\section{Film Thickness (Parabolic Film Approximation)}

Once the integration domain has been established, the film-thickness equation can be determined numerically. First, the load capacity $w$ is obtained from the numerically determined pressure distribution. Then inserting the value of $w$ into equation (14) allows us to solve for $L$ for various geometries.

From the data in table II, a curve fit can be effected as a function of geometry. Studying figure 4 and trying several appropriate functional forms to curve-fit the data showed that the following equation represented the data best:

$$
\mathrm{L}=\mathrm{a}_{1} \tan ^{-1} \frac{\alpha}{2}+\mathrm{a}_{0}
$$

The values of $a_{0}$ and $a_{1}$ were determined to be

$$
\left.\begin{array}{l}
a_{0}=1.683 \\
a_{1}=0.131
\end{array}\right\}
$$

The coefficient of determination $r^{2}$ (ref. 17) was 0.96 for this fit. The value of $r^{2}$ reflects the fit of the data to the resulting equation: 1 being a perfect fit, and 0 being the 
worst possible fit. Inserting equation (18) into equation (16) gives for the calculated mininum film thickness

$$
\tilde{\mathrm{H}}_{\min }=128 \alpha\left[\frac{\varphi \mathrm{U}}{\mathrm{W}}\left(0.131 \tan ^{-1} \frac{\alpha}{2}+1.683\right)\right]^{2}
$$

For comparison of the calculated film thickness with the actual input film thickness, it is convenient to define the differences (in percent) as

$$
\mathrm{D}=\left[\frac{\left(\tilde{\mathrm{H}}_{\min }-\mathrm{H}_{\min }\right)}{\mathrm{H}_{\min }}\right] \times 100
$$

The difference ranged from -2.14 to 1.35 percent (table II).

\section{Film Thickness (Exact Equation)}

The results of using the exact film -thickness equation (eq. (6)) rather than the parabolic approximation (eq. (7)) can be compared from the values of $\mathrm{L}$ given in table $\Pi$. The values of $L$ determined through the exact film-thickness analysis are always reduced by a constant factor. Thus the dependence on geometry and film thickness for the reduced hydrodynamic lift can be separated as follows:

$$
\mathrm{L}\left(\alpha, \mathrm{H}_{0}\right)=\epsilon\left(\mathrm{H}_{0}\right) \mathrm{L}_{\mathrm{p}}(\alpha)
$$

where $L_{p}$ is determined by using the parabolic approximation. The values of $\epsilon\left(\mathrm{H}_{0}\right)$ are given in table III. Using the parabolic approximation gives errors of 0.7 and 1.6 percent for film thicknesses of $10^{-5}$ and $10^{-4}$, respectively. Although these errors are quite small, they would probably be larger for thicker films: As the film thickness is in creased, the pressure distribution spreads out more evenly (e.g., fig. 5). Thus the pressures far from the point of contact, where the parabolic assumption is no longer valid, contribute more to the load capacity than if the pressure distribution had been very localized.

The minimum film thickness can now be written as

$$
\tilde{\mathrm{H}}_{\min }=128 \alpha\left[\frac{\epsilon \varphi \mathrm{U}}{\mathrm{W}}\left(0.131 \tan ^{-1} \frac{\alpha}{2}+1.683\right)\right]^{2}
$$

The difference ranges from 2.00 to -2.11 percent for the exact film-thickness results in table II. 


\section{DISCUSSION OF RESULTS}

\section{Comparison of Theories}

The minimum-film -thickness equation derived by Kapitza using half-Sommerfeld boundary conditions and assuming the parabolic approximation is

$$
\widetilde{\mathrm{H}}_{\min }=128 \alpha\left(\frac{\varphi \mathrm{U}}{\mathrm{W}} \frac{\pi}{2}\right)^{2}
$$

By equating equation (16) with this expression for a given speed parameter, the load capacity for the two theories can be compared; that is,

$$
\frac{\mathrm{W}}{\mathrm{W}_{\mathrm{Kap}}}=\frac{\mathrm{L}(\alpha)}{\left(\frac{\pi}{2}\right)}
$$

The effect of the geometry on the reduced hydrodynamic lift is shown in figure 4. The figure shows that $\mathrm{L}$, and hence the load capacity (eq. (25)), is 11 to 20 percent greater than that predicted by Kapitza. The least difference occurs for a ball-on-plate contact. As $\alpha$ is increased, the difference in load capacities approaches a constant 20 percent. The alteration of the pressure distribution due to the Reynolds boundary conditions at the cavitation boundary is responsible for this geometry effect. Figure 6 is a threedimensional representation of a pressure distribution for $\alpha$ of 1.00 and 36.54 and illustrates the shape of the cavitation boundary. As $\alpha$ becomes large, the cavitation boundary tends to straighten out, accompanied by decreasing changes in $\mathrm{L}$. The scale along the $y$-axis in figure 6(a) has been magnified about 3 times to improve the resolution. Consequently the differences in the shapes of the cavitation boundary are actually subdued as they are presented.

The two analyses resulted in the same exponent of 2 for U/W. Dalmaz (ref. 3), using the Reynolds boundary conditions for a ball-on-plate configuration, reported an exponent of 1.77. The lower exponent appears to be due to starvation effects resulting from the inlet condition in both the analytical and experimental results. This is illustrated more clearly by comparing the results of applying the inlet condition of Dalmaz and the inlet condition in this study, using Kapitza's classical theory for both. A fixed oil film thick ness at the inlet that is independent of the minimum film thickness is used in Dalmaz's analysis and in this study as well. But the inlet oil film thickness for the analysis of reference 3 and experimental work (given in ref. 18) was roughly 5 percent of that used here. The effect that this has on the exponent of $\mathrm{U} / \mathrm{W}$ can be seen by calculating the load capacity for two different film thicknesses while keeping the other hydrodynamic 
variables constant. Dimensionless minimum -film -thickness values of $10^{-4}$ and $10^{-5}$ result in load capacities of 0.046 and 0.151 newton, respectively. This would yield an exponent of 1.94. For thicker films (i.e., $\mathrm{H}_{0}=10^{-3}$ ) the starvation effects become even more pronounced and the $\mathrm{U} / \mathrm{W}$ exponent is driven down in value to 1.84. For comparison, from the data in table I for fully flooded conditions, we calculate the exponent to be 1.98 .

Figure 7 compares experimental data (ref. 3) taken under lightly loaded (rigid contacts), isoviscous conditions for pure sliding of a ball on a plate with the corresponding theoretical results. The parameter grouping in the figure is that used by Dalmaz (ref. 3) and first introduced by Thorp and Gohar (ref. 4). The theoretical results of this paper are in excellent agreement with the data for the lower half range of $\mathrm{H}_{0} / \mathrm{WG}$. For the reasons previously explained, the agreement of these results with the experimental results of reference 3 begins to diverge for the upper range of $\mathrm{H}_{0} / \mathrm{WG}$. Further, using comparable inlet conditions for both theory and experiment provides better agreement between the two for the upper range of $\mathrm{H}_{0} / \mathrm{WG}$, as the theoretical line of Dalmaz attests in figure 7. For comparison, the theory by Kapitza has been included.

\section{Contour Plots}

Isobar plots for three radius ratios (i. e. , $\alpha$ of $25.29,8.30$, and 1.00) are shown in figure 8. The contours were generated by means of a contour-plotting subroutine and displayed with a Calcomp plotter. The contours belong to the family of curves defined by equation (10). The center of contact is represented by the asterisk. The pressure peak builds up in the entrance region, which is located to the left of the center of contact and is indicated by the + . Since the isobars in each case are evenly spaced, the pressure gradients can be easily depicted. Note that, as the radius ratio increases, the steeper pressure gradients are predominantly along the rolling direction. This implies that the amount of side leakage decreases as $\alpha$ increases. A decrease in side leakage is reflected in an increase in the value of $\varphi$. For line contact $\varphi=1$ and for the largest value of $\alpha$ in this investigation $(\alpha=36.54) \varphi=0.998$.

\section{Pressure Profiles}

Pressure profiles across the center of the conjunction and in the direction of rolling are shown in figure 9 for three radius ratios (i. e., $\alpha$ of $36.54,2.84$, and 1.00). The pressures were generated for a constant dimensionless film thickness $\left(\mathrm{H}_{0}=10^{-4}\right)$. The locations of the pressure peaks were not altered by the fact that Reynolds boundary conditions were used rather than half-Sommerfeld boundary conditions. The locations of the 
pressure peaks from reference 1 are determined by setting $(\partial P / \partial X)=(\partial P / \partial Y)=0$ and solving for $\mathrm{X}$ and $\mathrm{Y}$ as follows:

$$
\left.\begin{array}{c}
\mathrm{x}_{\mathrm{pk}}=-\sqrt{\frac{2 \mathrm{H}_{0}}{3}} \\
\mathrm{Y}_{\mathrm{pk}}=0
\end{array}\right\}
$$

Equation (26) shows that the geometry does not affect the pressure peak location, as can be verified by the numerically determined curves of figure 9. However, the magnitude of the pressure peaks will, according to equation (10), be modulated by the ArchardCowking side-leakage factor $\varphi$, which is a function of the geometry. The influence of the side-leakage factor on the pressure distribution for several geometries is shown in figure 9.

\section{CONCLUDING REMARKS}

The influence of geometry on the isothermal hydrodynamic film separating two rigid solids was investigated. The investigation was conducted for a conjunction fully im mersed in lubricant (i. e. , fully flooded). The effect of the geometry on the film thickness was determined by varying the radius ratio from 1 (a ball -on-plate configuration) to 36 (a ball in a conforming groove). The dimensionless film thickness was varied from $10^{-5}$ to $10^{-4}$. Pressure-viscosity effects were not considered. It was found that the mininum film thickness had the same speed, viscosity, and load dependence as Kapitza's classical solution. However, the incorporation of the Reynolds boundary conditions resulted in an additional geometry effect. That is, the film-thickness equations can be compared as follows:

$$
\begin{aligned}
& \mathrm{H}_{0}=128 \alpha\left[\epsilon\left(\mathrm{H}_{0}\right) \frac{\varphi \mathrm{U}}{\mathrm{W}}\left(0.131 \tan ^{-1} \frac{\alpha}{2}+1.683\right)\right]^{2}\left\{\begin{array}{l}
\text { Full circular film; } \\
\text { Reynolds boundary conditions }
\end{array}\right. \\
& \mathrm{H}_{0}=128 \alpha\left[\frac{\varphi \mathrm{U}}{\mathrm{W}}\left(0.131 \tan ^{-1} \frac{\alpha}{2}+1.683\right)\right]^{2} \quad\left\{\begin{array}{l}
\text { Parabolic approximation; } \\
\text { Reynolds boundary conditions }
\end{array}\right. \\
& \mathrm{H}_{0}=128 \alpha\left(\frac{\varphi \mathrm{U}}{\mathrm{W}} \frac{\pi}{2}\right)^{2}\left\{\begin{array}{l}
\text { Parabolic approximation; } \\
\text { half -Sommerfeld boundary } \\
\text { conditions }
\end{array}\right.
\end{aligned}
$$


where $\mathrm{H}_{0}$ is the dimensionless central (minimum) film thickness; $\alpha$ is the radius ratio $R_{y} / R_{x} ; \epsilon$ is the film-thickness effect on reduced hydrodynamic lift; $\varphi$ is the ArchardCowking side-leakage factor; and $\mathrm{U} / \mathrm{W}$ is the ratio of dimensionless speed to dimensionless load. The Reynolds boundary conditions resulted in the predicted load capacity being 11 to 20 percent greater than if half-Sommerfeld boundary conditions were used.

The parabolic approximation resulted in overestimations of the minimum film thickness of about 1.6 and 0.7 percent for calculated dimensionless film thicknesses of $10^{-4}$ and $10^{-5}$, respectively.

Lewis Research Center,

National Aeronautics and Space Administration,

Cleveland, Ohio, May 12, 1978, $505-04$. 


\section{APPENDIX - COMPUTER PROGRAM}

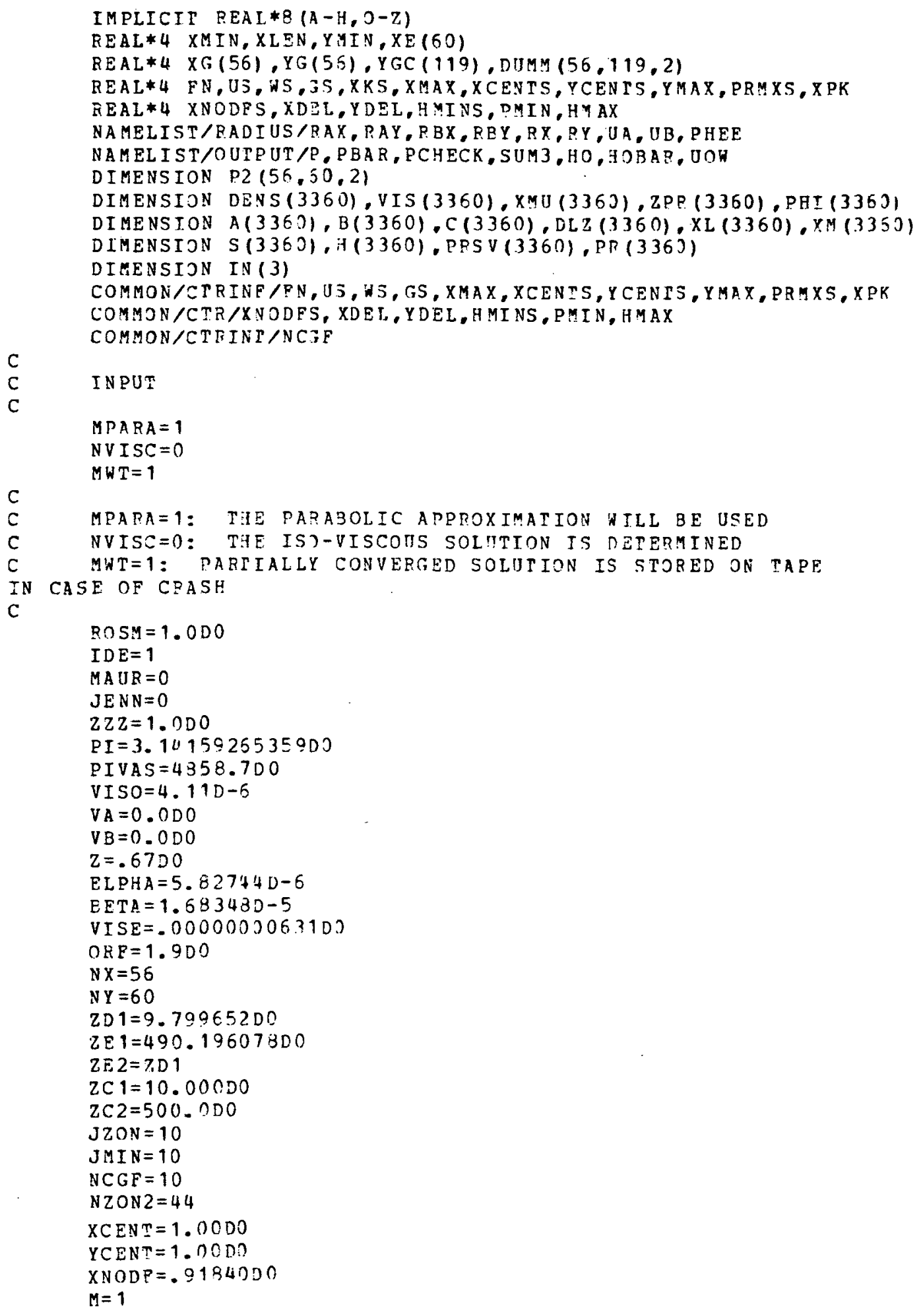




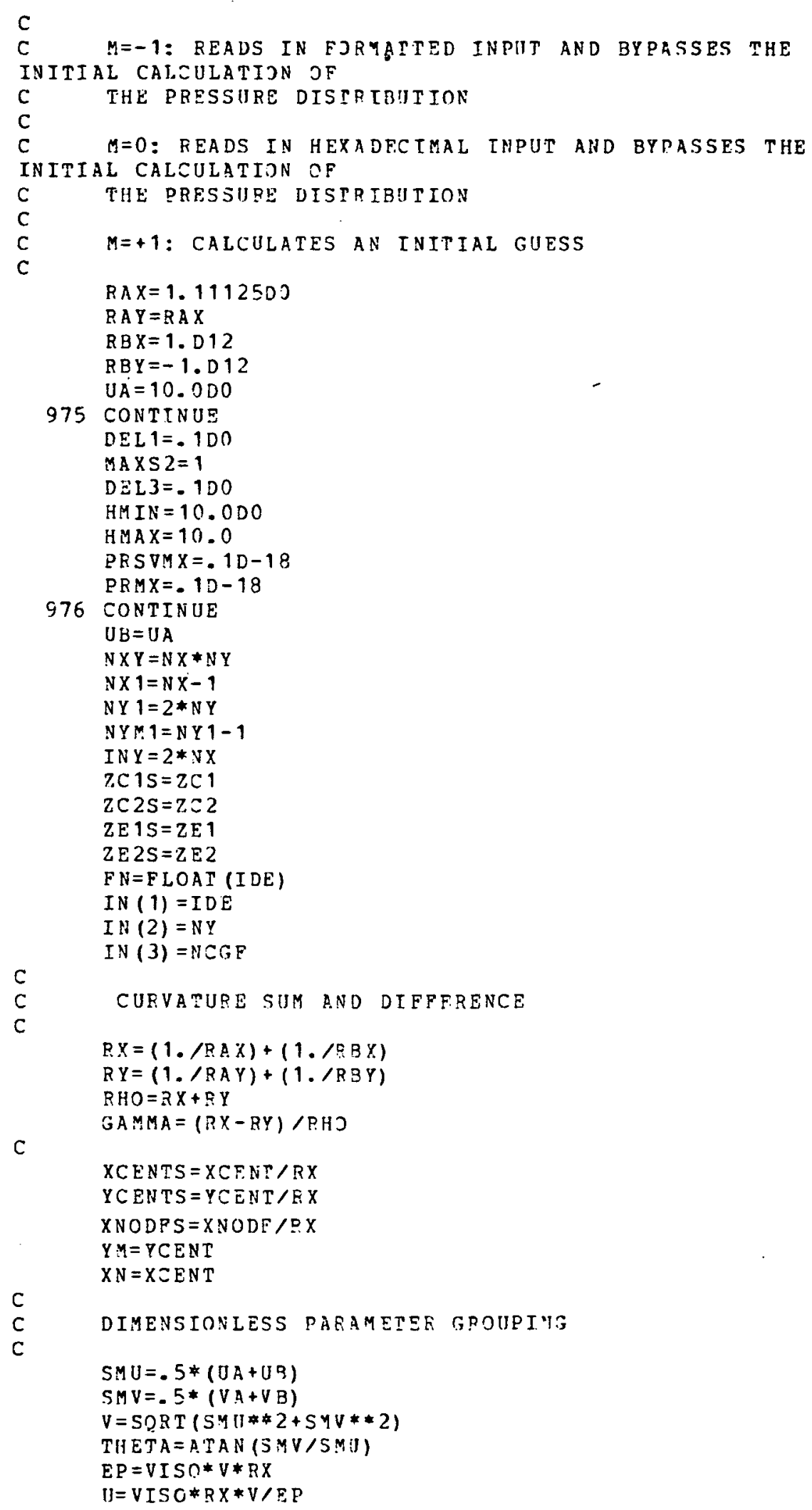




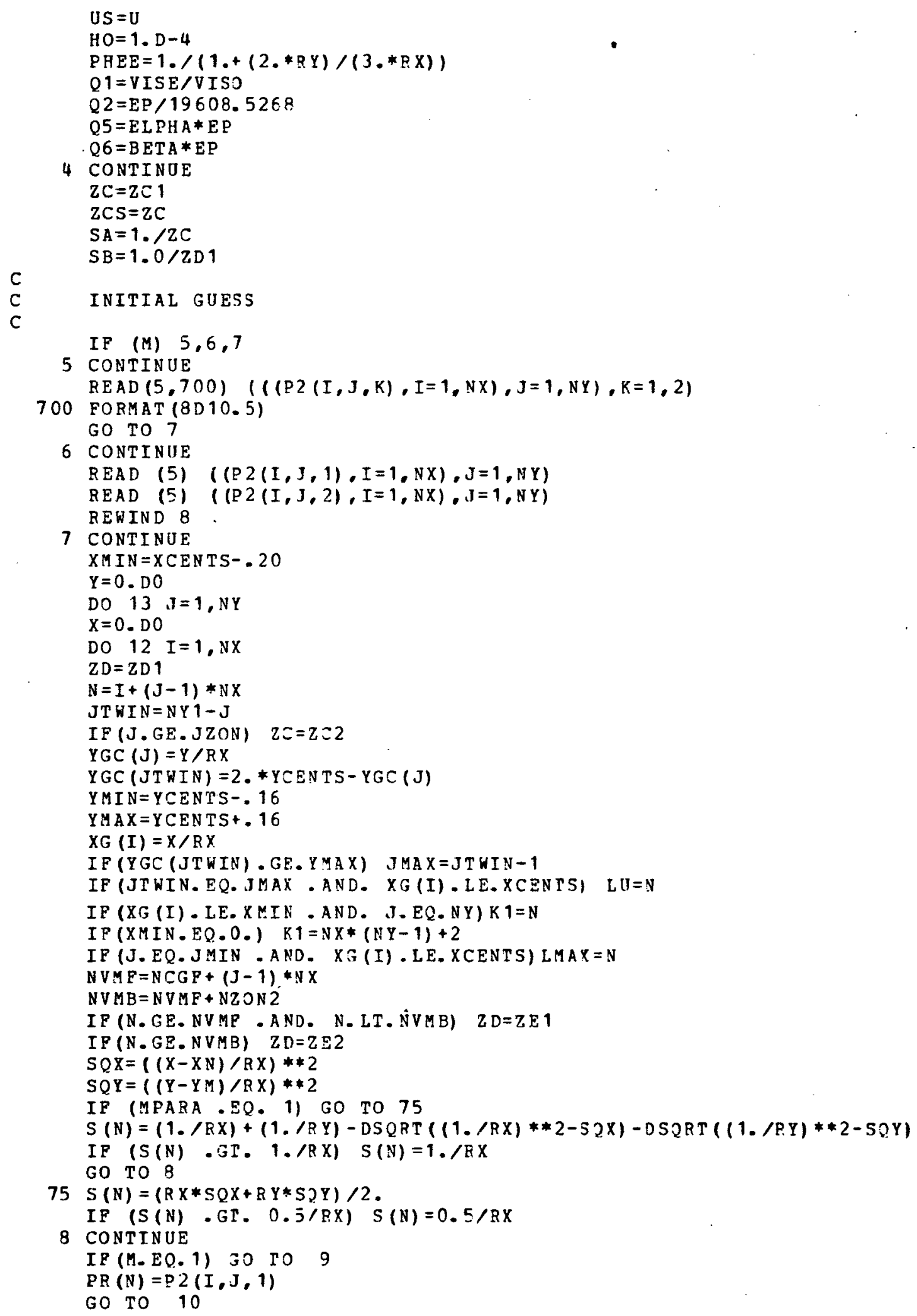


9 CONTINUE

$P R(N)=.1 D-8$

10 CONTINUE

IF (J.EQ.1 .JR. I. EQ. 1 .OR. I.EQ.NX) $P Q(N)=0.0 D 0$

IF (PR (N).GT.0.) 33 TO 11

$P R(N)=0 . D O$

$11 \operatorname{PRSV}(N)=F[(N)$

$\operatorname{IP}(J . E Q . N Y) \quad Y G(I)=P R(N)$

IF (PR (N). LT.PRSVMX) GO TO 12

PRS $M M X=P R(N)$

NHOLD $=\mathrm{N}$

$12 x=x+1 . / 2 D$

$13 Y=Y+1 . / Z C$

$X M A X=X G(N X)$

$Y D E L=Y M A X-Y M I N$

$X D E L=Y D E L$

KRITE $(6,900) \quad(P R(N), N=1, N X Y)$

900 FORMAT $(1 \mathrm{H}, 2 \mathrm{HPR} / 70(1 \mathrm{H}, 10 \mathrm{D} 13.5 /))$

WRITE $(6,1000) \quad(S(N), N=1, N X Y)$

C

1000 PORMAT $(1 \mathrm{H}, 1 \mathrm{HS} / 7)(1 \mathrm{H}, 10 \mathrm{D} 13.5 / 1)$

C FILM THICKNESS

C

14 CONTINUE

DO $19 \mathrm{~J}=1, \mathrm{NY}$

DO $18 \quad I=1, N X$

$\mathrm{N} 3=\mathrm{I}+(\mathrm{J}-1) * \mathrm{NX}$

$\mathrm{H}(\mathrm{N} 3)=\mathrm{HO}+\mathrm{R} X * \mathrm{~S}(\mathrm{~N} 3)$

IP (H(N3).GT.GMIN) 35 TO 17

HMIN $=\mathrm{H}(\mathrm{N} 3)$

HMINS $=$ HMIN

$\mathrm{NSAVE}=\mathrm{N} 3$

17 CONTINUE

PHI $(N 3)=P R(N 3) *(H(N 3) * * 1.5)$

18 CONTINUE

19 CONTINUE

WRITE $(6,1103)$ NSAVE, HMIN

1100 FORMAT $(1 \mathrm{H}, 6 \mathrm{H}$ NSAVE $=, \mathrm{I} 10,10 \mathrm{X}, 5 \mathrm{HHMIN}=, 015.5)$

WRITE $(6,1203)$ PRSVMX, NHOLD

1200 PORMAT $(1 \mathrm{H}, 8$ HPRSVYX $=.016 .5,10 \times, 7$ HNHOLD $=$, I 101

20 CONTINUE

NRITE (6, RADIUS)

C

$\mathrm{C}$

INITIAL VISOJSITY AND DENSITY CALCULATION

DO $21 N=1, N \times Y$

DENS $(N)=1 .+(Q 5 * P R(N)) /(1 .+Q 6 * P R(N))$

$\operatorname{VIS}(N)=Q 1 * *(1 .-(1 .+Q 2 * P R(N)) * * Z)$

$X M U(N)=D E N S(N) / V I S(N)$

21 CONTINUE

c

C

RELAXATION CJEFFIENTS A,B,C,D, L, AND M

22 CONTINUE

$S U M=0.0 D O$

$\mathrm{ZC}=Z \mathrm{C} 1$

$\mathrm{ZF}=7 . \mathrm{C} 1$

DO $24 \mathrm{~J}=2, \mathrm{NY}$

DO $23 \quad I=2, N \times 1$

$2 D=Z D 1$

$Z E^{\prime}=Z D$ 


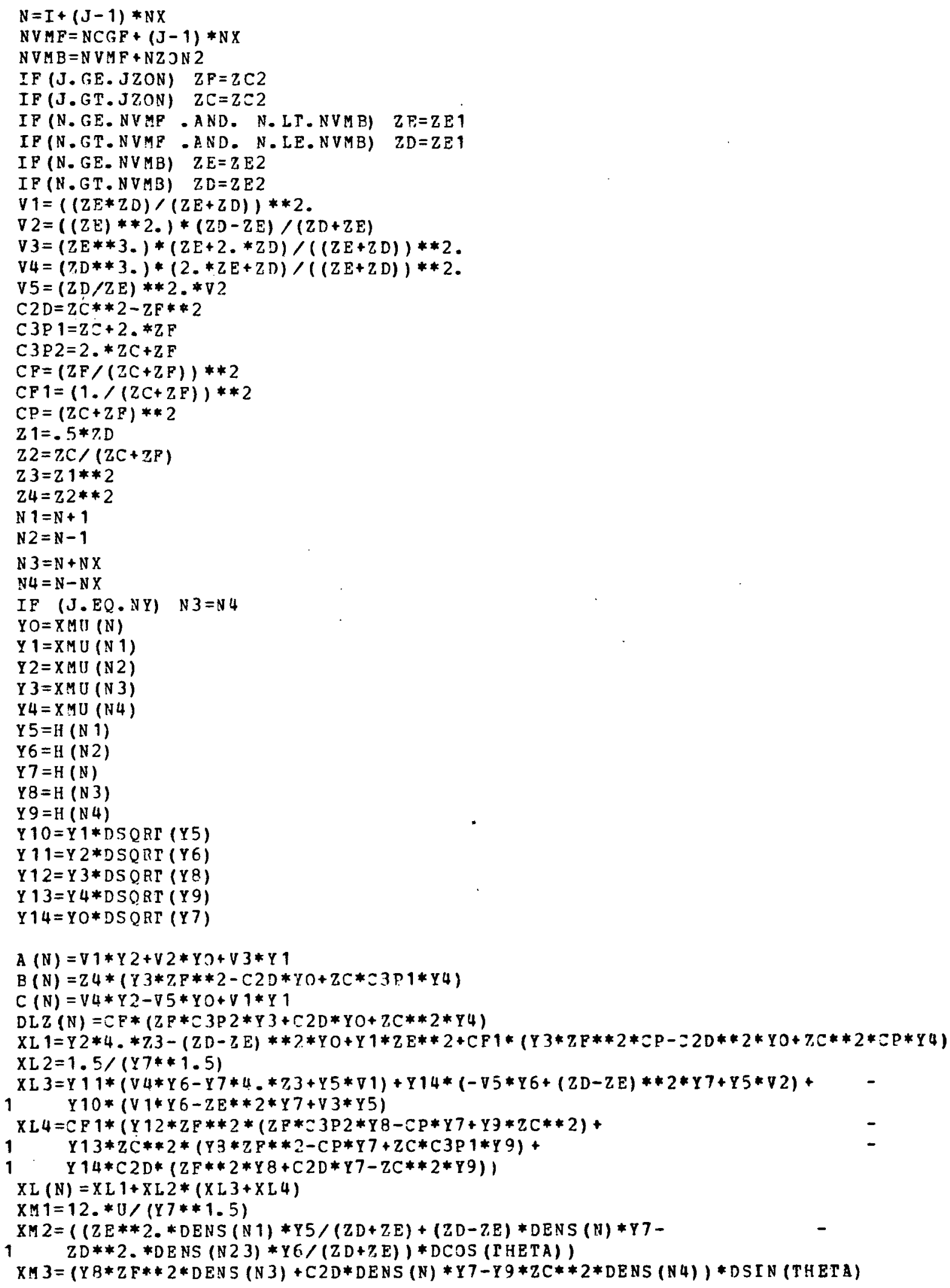




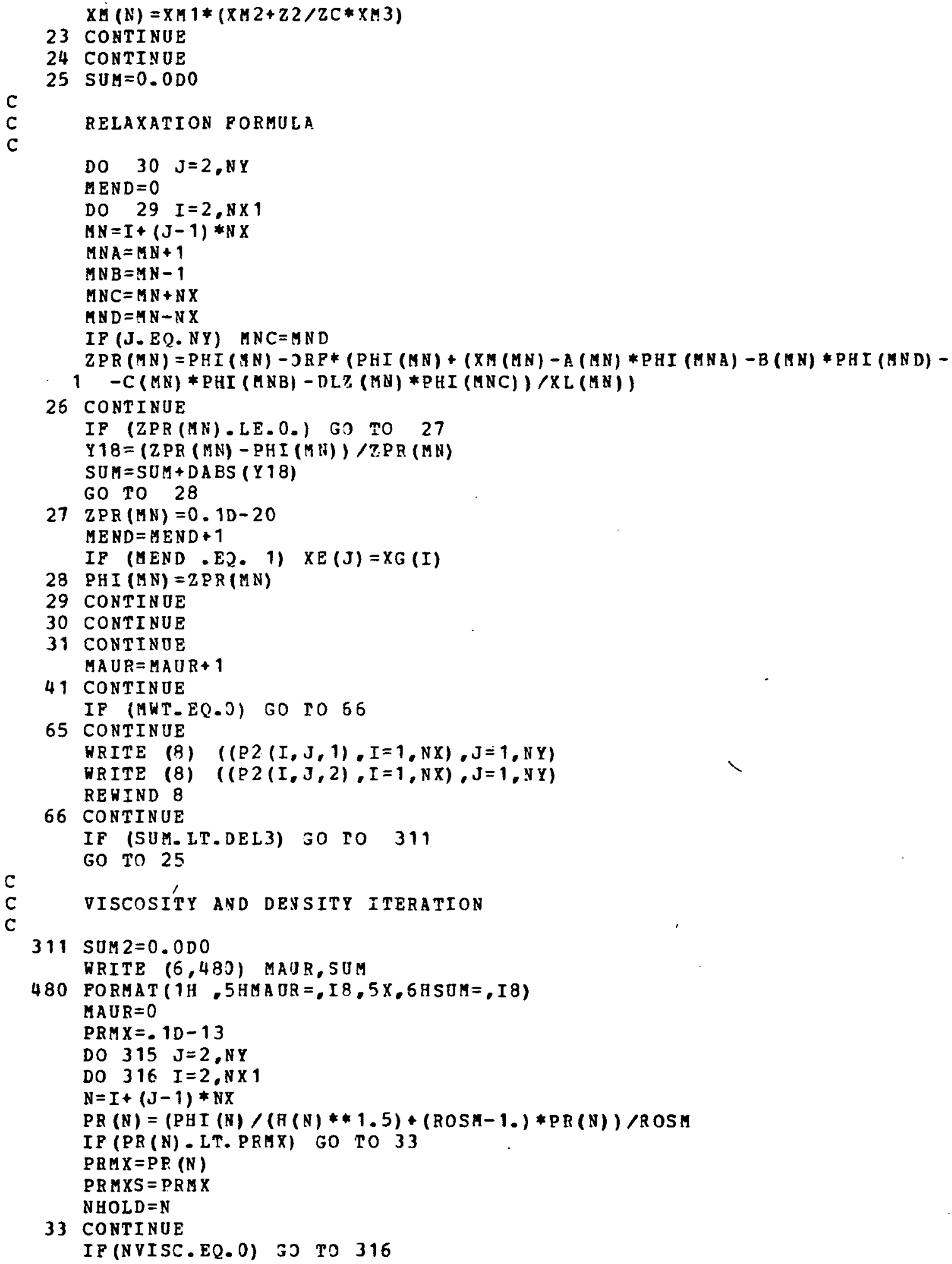




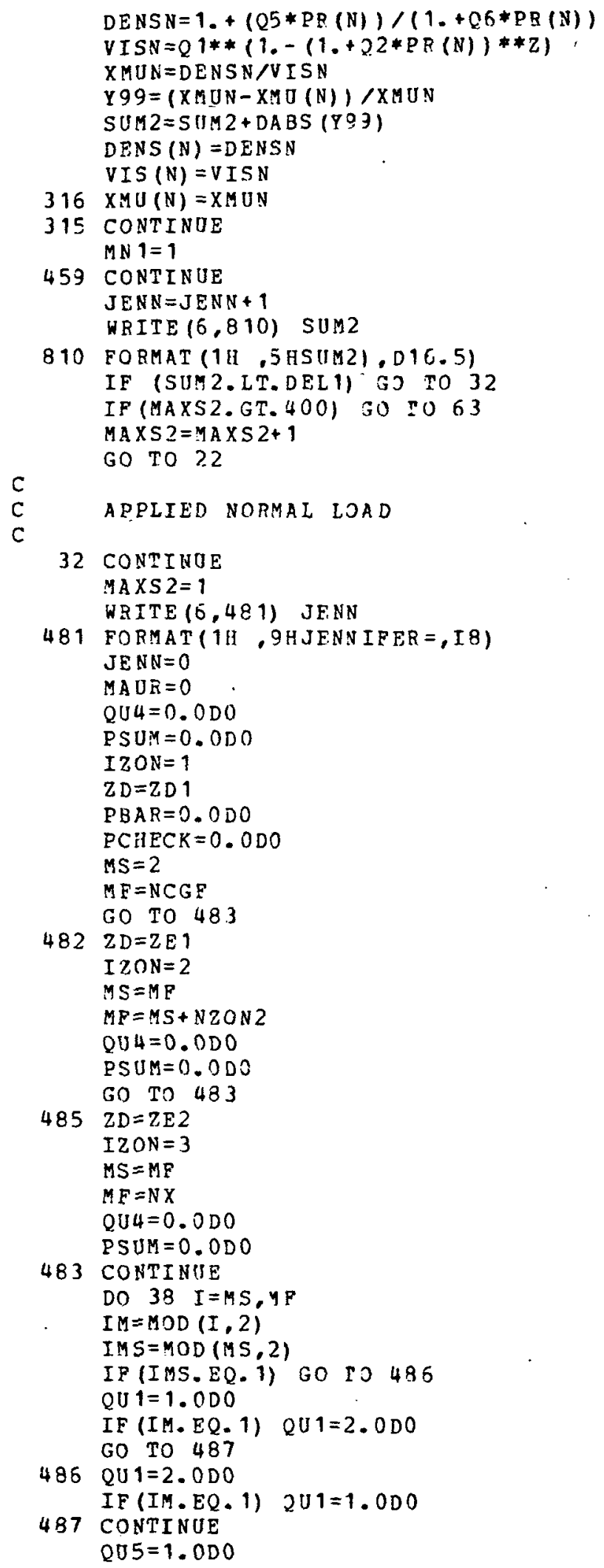




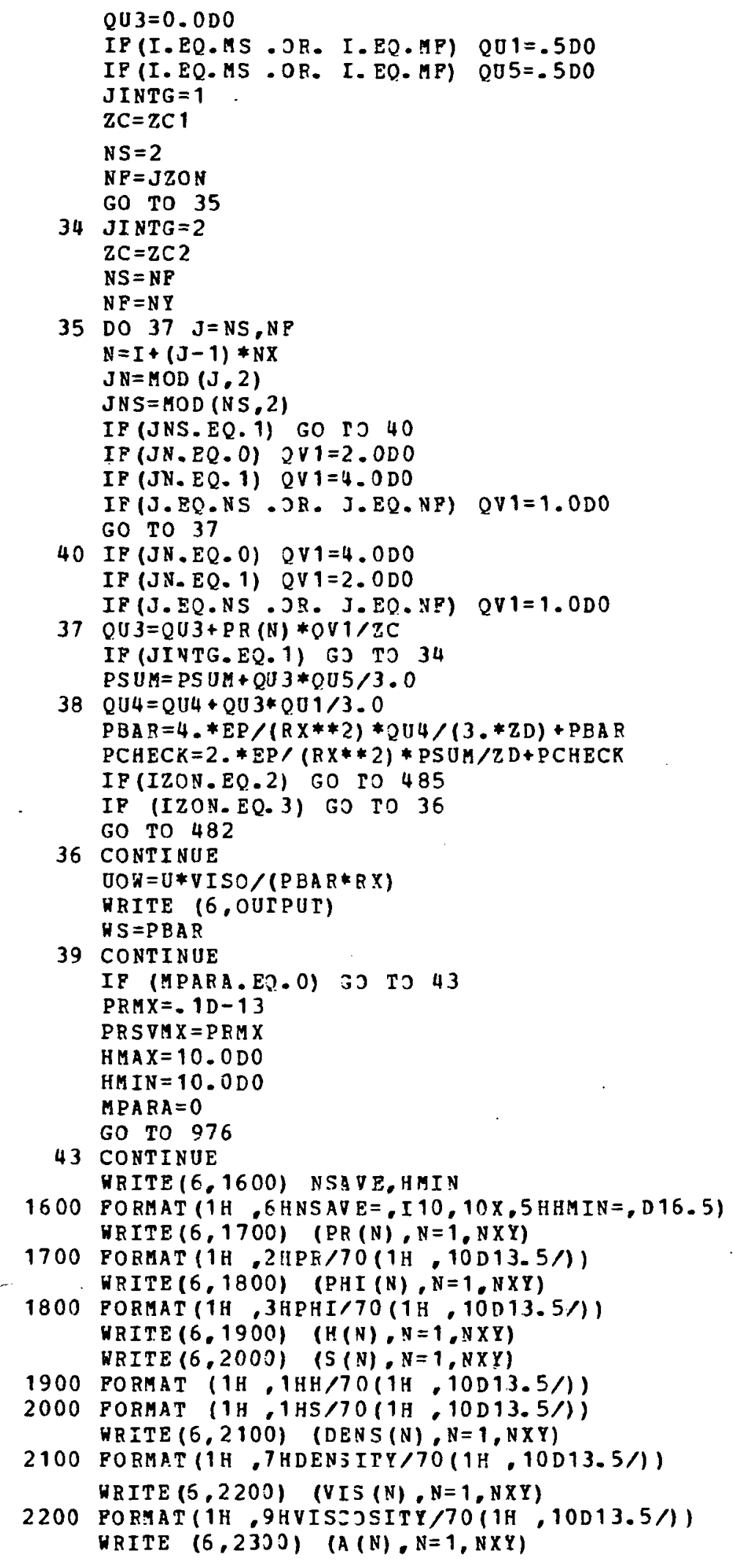




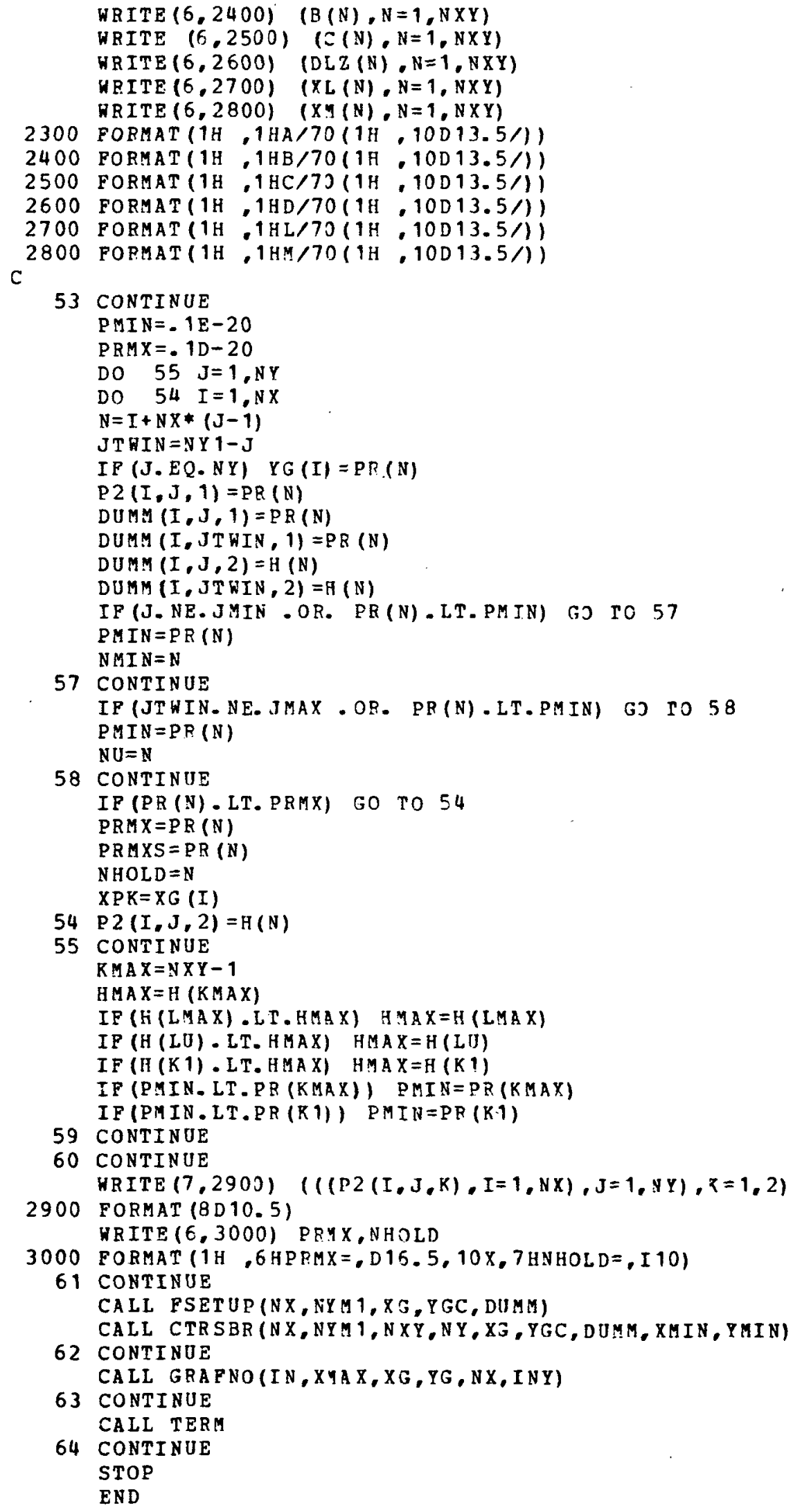




\section{REFERENCES}

1. Kapitza, P. L.: Hydrodynamic Theory of Lubrication During Rolling. Zh. Tekh. Fiz., vol. 25, no. 4, 1955, pp. 747-762.

2. Martin, H. M.: The Lubrication of Gear-Teeth. Engineering (London), vol. 102, 1916, pp. 119-121.

3. Dalmaz, G. ; and Godet, M.: Traction, Load, and Film Thickness in Lightly Loaded Lubricated Point Contacts. J. Mech. Eng. Sci., vol. 15, no. 6, Dec. 1973, pp. $400-409$.

4. Thorp, N.; and Gohar, R.: Oil Film Thickness and Shape for a Ball Sliding in a Grooved Raceway. J. Lubr. Technol., vol. 94, July 1972.

5. Howlett, J.: Film-Lubrication Between Spherical Surfaces: With an Application to the Theory of the Four-Ball Lubricant Testing Instrument. J. Appl. Phys., vol. 17, no. 3, Mar. 1946, pp. 137-149.

6. Korovchinskii, M. V.: Possible Limiting Conditions of Hydrodynamic Friction in the Four-Ball Testing Machine. Frict. Wear Mach. (USSR), vol. 12, 1958, pp. 233-273.

7. Hamrock, Bernard J.; and Dowson, Duncan: Isothermal Elastohydrodynamic Lubrication of Point Contacts. I - Theoretical Formulation. NASA TN D-8049, 1975; also J. Lubr. Technol., vol. 98, Apr. 1976, pp. 223-229.

8. Hamrock, Bernard J.; and Dowson, Duncan: Isothermal Elastohydrodynamic Lubrication of Point Contacts. II - Ellipticity Parameter Results. NASA TN D-8166, 1976; also J. Lubr. Technol., vol. 98, July 1976, pp. 375-383.

9. Hamrock, Bernard J.; and Dowson, Duncan: Isothermal Elastohydrodynamic Lubrication of Point Contacts. III - Fully Flooded Results. J. Lubr. Technol., vol. 99, Apr. 1977, pp. 264-276.

10. Hamrock, Bernard J.; and Dowson, Duncan: Isothermal Elastohydrodynamic Lubrication of Point Contacts. IV - Starvation Results. J. Lubr. Technol. , vol. 99, Jan. 1977, pp. 15-23.

11. Archard, J. F.; and Cowking, E. W.: Elastohydrodynamic Lubrication at Point Contacts. Proc. Inst. Mech. Eng. (London), vol. 180, pt. 3B, 1965-66, pp. 47-56.

12. Sommerfeld, A.: The Hydrodynamic Theory of Lubrication Friction. Z. Math. Phys., vol. 50, no. 1-2, 1904, pp. 97-155. 
13. Dowson, D.: Investigation of Cavitation in Lubricating Films Supporting Small Loads. Conference on Lubrication and Wear, Proceedings of the Institution of Mechanical Engineers (London), 1957, pp. 93-99.

14. Taylor, C. M.: Separation Cavitation; Solutions for the Infinite Width Cylinder Plane and Journal Bearing Configurations. J. Mech. Eng. Sci., vol. 15, no. 3, 1973, pp. $237-239$.

15. Vogelpohl, Georg: Beitrage zur Kenntnis der Gleitlagerreibung (A Treatise on Friction in Sliding Bearings). V. D. I. Forschungsh. no. 386, 1937.

16. Dowson, D.: The Inlet Boundary Condition. Cavitation and Related Phenomena in Lubrication, D. Dowson, M. Godet, and C. M. Taylor, eds., Mechanical Engineering Publications, Ltd., New York, 1975, pp. 143-152.

17. Spiegel, Murray R.: Schaum's Outline of Theory and Problems of Statistics. McGraw-Hill Book Co., Inc., 1961.

18. Dalmaz, G.; and Godet, M. : An Apparatus for the Simultaneous Measurement of Load, Traction, and Film Thickness in Lubricated Sliding Point Contacts, Tribology, vol. 5, no. 3, 1972, pp. 111-117.

TABLE I. - ESTIMATE OF PERCENT LOSS OF LOAD CAPACITY FOR

VARIOUS GEOMETRIES AND INTEGRATION DOMAINS

\begin{tabular}{|c|c|c|c|c|c|c|}
\hline \multirow{2}{*}{$\begin{array}{c}\text { Minimum } \\
\text { film } \\
\text { thickness, } \\
\mathrm{H}_{0}\end{array}$} & \multirow{2}{*}{$\begin{array}{c}\text { Radius } \\
\text { ratio, } \\
\alpha\end{array}$} & \multicolumn{2}{|c|}{ Inlet parameter } & \multicolumn{2}{|c|}{ Load capacity } & \multirow{2}{*}{$\begin{array}{l}\text { Loss of load } \\
\text { capacity, } \\
\text { m, } \\
\text { percent }\end{array}$} \\
\hline & & $\begin{array}{r}\text { Abcissa } \\
-\mathrm{X}_{E}\end{array}$ & $\begin{array}{c}\text { Ordinate } \\
{ }_{ \pm Y_{E}}\end{array}$ & $\begin{array}{c}\text { Finite } \\
\text { domain, } \\
w(N)\end{array}$ & $\begin{array}{c}\text { Infinite } \\
\text { domain, } \\
\mathrm{w}_{\infty}(\mathrm{N})\end{array}$ & \\
\hline \multirow{13}{*}{$\begin{array}{l}10^{-5} \\
10^{-5} \\
10^{-4}\end{array}$} & 36.5361 & \multirow[t]{13}{*}{1.00} & 7.00 & 1.5162 & 1.5237 & 0.49 \\
\hline & 1.0000 & & 1.00 & .1532 & .1540 & .51 \\
\hline & 36,5361 & & 7.00 & .4744 & .4818 & 1.55 \\
\hline & 25.2897 & & & .3917 & .3977 & 1.50 \\
\hline & 15. 8434 & & & .3055 & .3100 & 1.46 \\
\hline & 11.8266 & & $y$ & .2604 & .2642 & 1.45 \\
\hline & 8.3033 & & 4.00 & .2133 & .2165 & 1.50 \\
\hline & 5.2073 & & 4.00 & .1635 & .1659 & 1.46 \\
\hline & 3.9983 & & 2.00 & .1369 & .1391 & 1.61 \\
\hline & 2.8428 & & 2.00 & .1091 & .1109 & 1.54 \\
\hline & 2.3213 & & 2.00 & .0946 & .0961 & 1.51 \\
\hline & 1.3978 & & 1.34 & .0640 & .0650 & 1.56 \\
\hline & 1.0000 & & 1.00 & .0479 & .0487 & 1.61 \\
\hline
\end{tabular}


TABLE II. - DATA SHOWING EFFECT OF GEOMETRY ON

\section{MINIMUM FILM THICKNESS}

[Average surface velocity in $\mathrm{x}$-direction, $\mathrm{u}, 10 \mathrm{~cm} / \mathrm{sec}$; fluid vis cosity, $\nu_{0}, 0.411 \times 10^{-5} \mathrm{~N} \cdot \mathrm{sec} / \mathrm{cm}^{2}$; effective radius of curvature, $\left.R_{\mathrm{x}}, 1.11125 \mathrm{~cm}.\right]$

\begin{tabular}{|c|c|c|c|c|c|}
\hline \multirow{2}{*}{$\begin{array}{c}\text { Radius } \\
\text { ratio, } \\
\alpha\end{array}$} & \multirow{2}{*}{$\begin{array}{c}\text { Load } \\
\text { capacity, } \\
\text { w(N) }\end{array}$} & \multirow{2}{*}{$\begin{array}{c}\text { Reduced } \\
\text { hydro- } \\
\text { dynamic } \\
\text { lift, } \\
\text { L }\end{array}$} & \multicolumn{2}{|c|}{ Minimum film thickness } & \multirow{2}{*}{\begin{tabular}{|} 
Difference be- \\
tween $\mathrm{H}_{\mathrm{min}}$ \\
and $\widetilde{\mathrm{H}}_{\mathrm{min}}$ \\
$\mathrm{D}$, \\
percent,
\end{tabular}} \\
\hline & & & $\begin{array}{l}\text { Inputted } \\
\text { value, } \\
\mathrm{H}_{\text {min }}\end{array}$ & $\begin{array}{l}\text { Calculated } \\
\text { from } \\
\text { equation, } \\
\widetilde{\mathrm{H}}_{\text {min }}\end{array}$ & \\
\hline \multirow[t]{4}{*}{36.5361} & 1.8450 & 1.9020 & $10^{-5}$ & $a_{0.9785 \times 10^{-5}}$ & -2.14 \\
\hline & 1.8392 & 1.8960 & $10^{-5}$ & .9789 & -2.11 \\
\hline & .5749 & 1. 8741 & $10^{-4}$ & $a_{1.0079 \times 10^{-4}}$ & .79 \\
\hline & .5704 & 1. 8595 & & 1.0075 & .75 \\
\hline 25.2897 & .4738 & 1.8714 & & $a_{1.0075}$ & .75 \\
\hline 25.2897 & .4701 & 1.8568 & & 1.0072 & .72 \\
\hline 15.8434 & .3681 & 1.8652 & & $a_{1.0078}$ & .78 \\
\hline 15. 8434 & .3653 & 1. 8510 & & 1.0070 & .70 \\
\hline 11. 8266 & .3128 & 1.8592 & & 1.0079 & .79 \\
\hline 11. 8266 & .3104 & 1.8449 & & 1.0072 & .72 \\
\hline 8. 3033 & .2571 & 1.8658 & & ${ }^{2} .9919$ & -.81 \\
\hline 8. 3033 & .2552 & 1.8520 & & .9907 & -.93 \\
\hline 5. 2973 & .1955 & 1. 8501 & & a. 9900 & -1.00 \\
\hline 5. 2973 & .1940 & 1. 8360 & & .9894 & -1.06 \\
\hline 3.9983 & .1627 & 1.8367 & & a. 9899 & -1.00 \\
\hline 3.9983 & .1615 & 1.8232 & & .9887 & -1.13 \\
\hline 2.8428 & .1284 & 1.8206 & & a. 9880 & -1.20 \\
\hline 2. 8428 & .1274 & 1.8065 & & .9876 & -1.24 \\
\hline 2.3213 & .1105 & 1.8074 & & a. 9878 & -1.22 \\
\hline 2.3213 & .1097 & 1.7943 & & .9863 & -1.37 \\
\hline 1. 3978 & .0727 & 1.7543 & & ${ }^{a} 1.0061$ & .61 \\
\hline 1. 3978 & .0720 & 1.7384 & & 1.0094 & .94 \\
\hline \multirow[t]{4}{*}{1.0000} & .0537 & 1.7305 & & $a_{1.0135}$ & 1.35 \\
\hline & .0531 & 1.7121 & & 1.0200 & 2.00 \\
\hline & .1719 & 1.7533 & $10^{-5}$ & a. 9891 & -1.09 \\
\hline & .1713 & 1.7472 & $10^{-5}$ & .9901 & -.99 \\
\hline
\end{tabular}

${ }^{\mathrm{a}}$ Calculated by using the parabolic film assumption in theory. 
TABLE III. - EFFECT OF

\section{FRM THICKNESS ON}

REDUCED HYDRO-

DYNAMIC LIFT

\begin{tabular}{|c|c|}
\hline $\begin{array}{c}\text { Dimensionless } \\
\text { minimum film } \\
\text { thickness, } \\
\mathrm{H}_{\mathrm{min}}\end{array}$ & $\begin{array}{c}\text { Effect of } \mathrm{H}_{\mathrm{min}} \\
\text { on reduced } \\
\text { hydrodynamic } \\
\text { lift, } \\
\epsilon\left(\mathrm{H}_{\mathrm{min}}\right)\end{array}$ \\
\hline $10^{-4}$ & $\begin{array}{c}0.992 \\
.997 \\
10^{-5}\end{array}$ \\
\hline
\end{tabular}

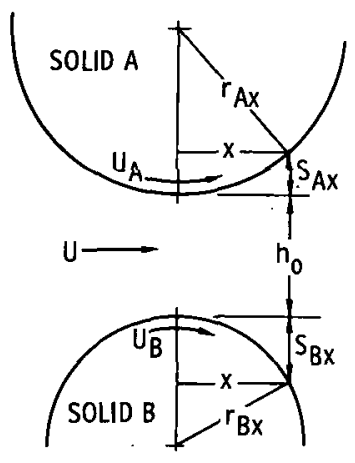

(a-1) $y=0$ plane.

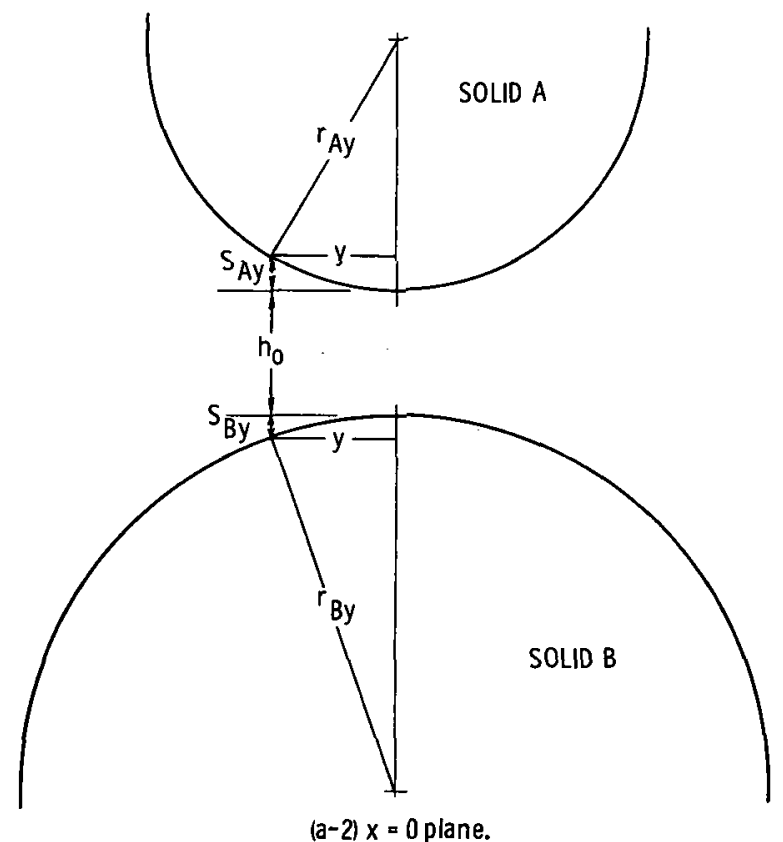

(a) Two rigid solids separated by a lubricant film.

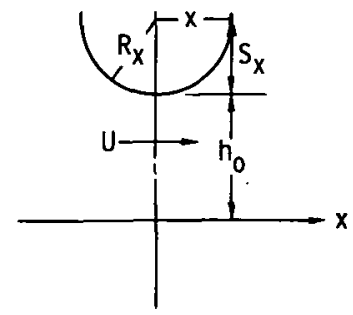

(b-1) $y=0$ ?

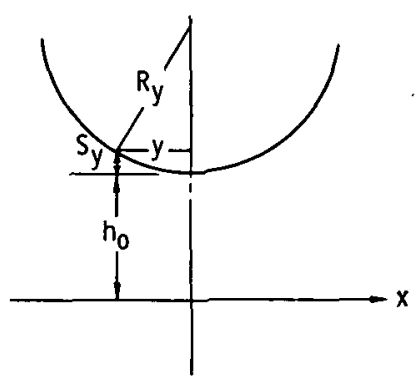

$(b-2) x=0$ plane.

(b) Equivalent system of a rigid solid near a plane separated by a lubricant film.

Figure 1. - Contact geometry. 

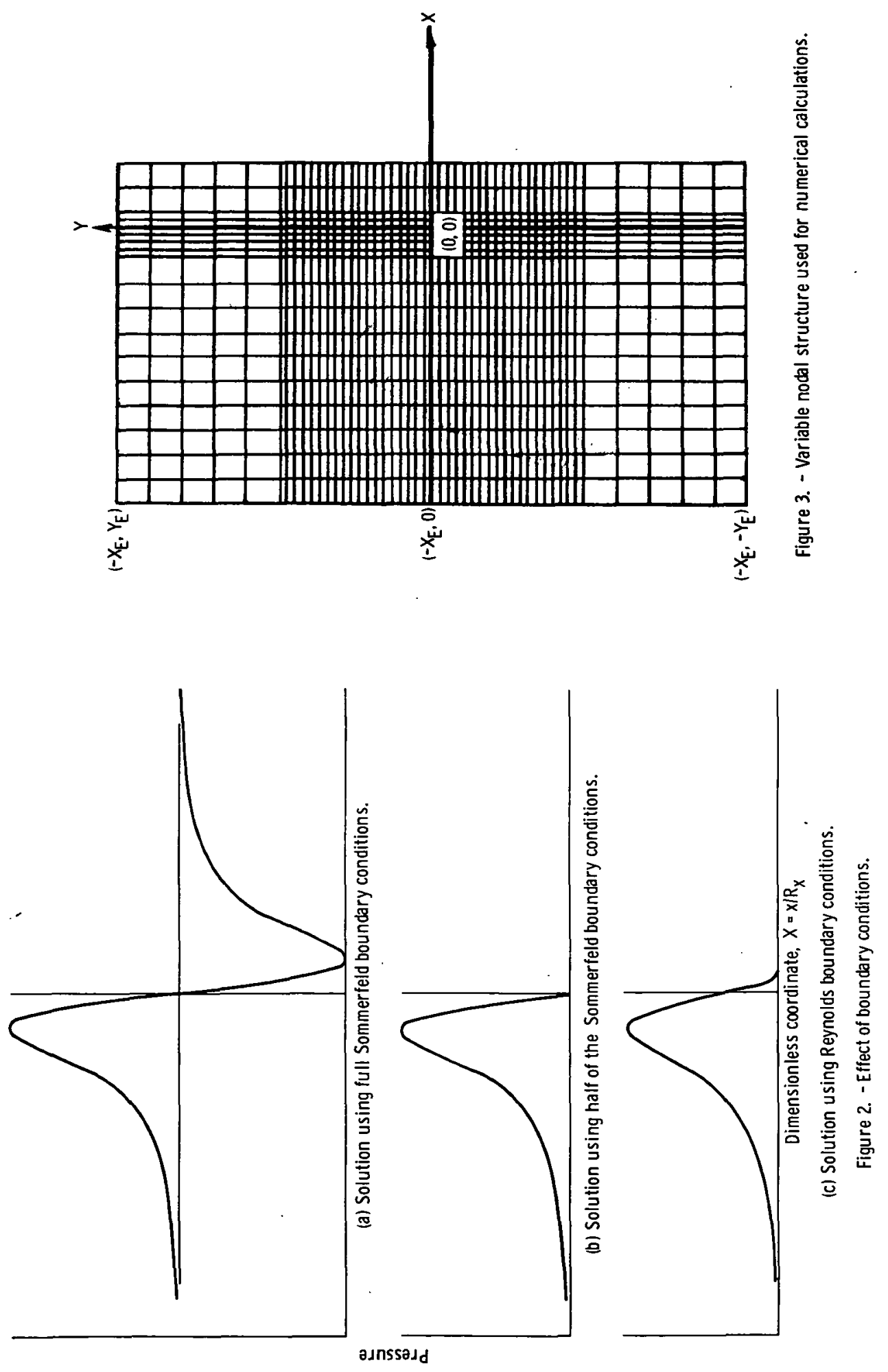


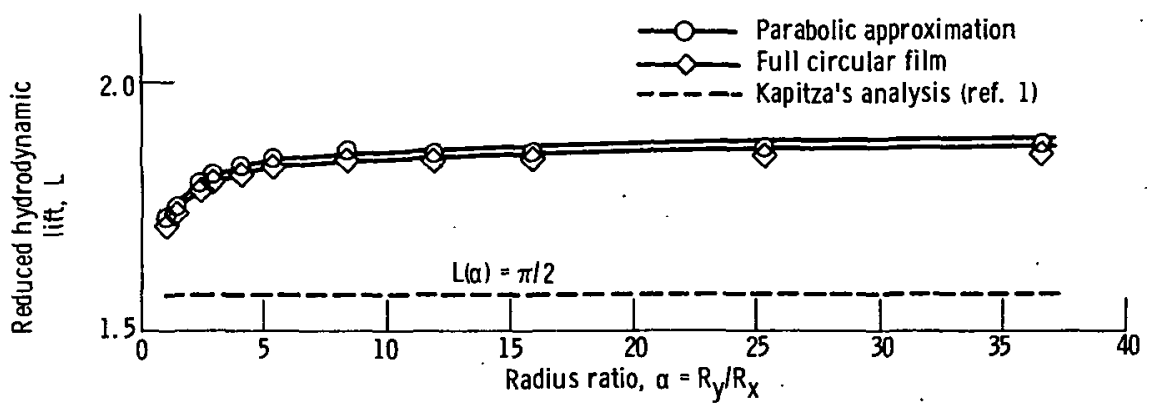

Figure 4. - Effect of radius ratio on reduced hydrodynamic lift.

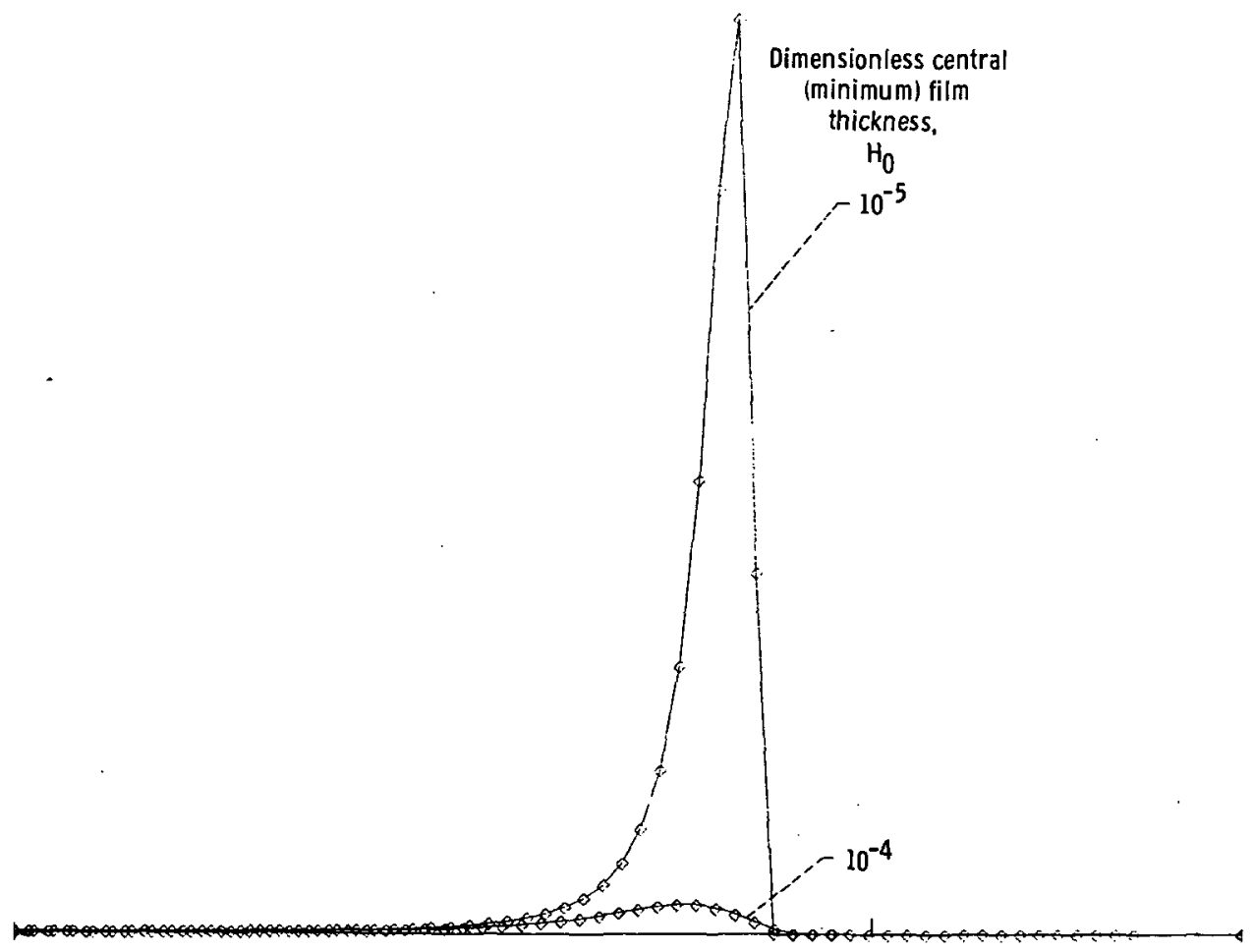

Figure 5. - Pressure profiles along rolling direction for two film thicknesses. 


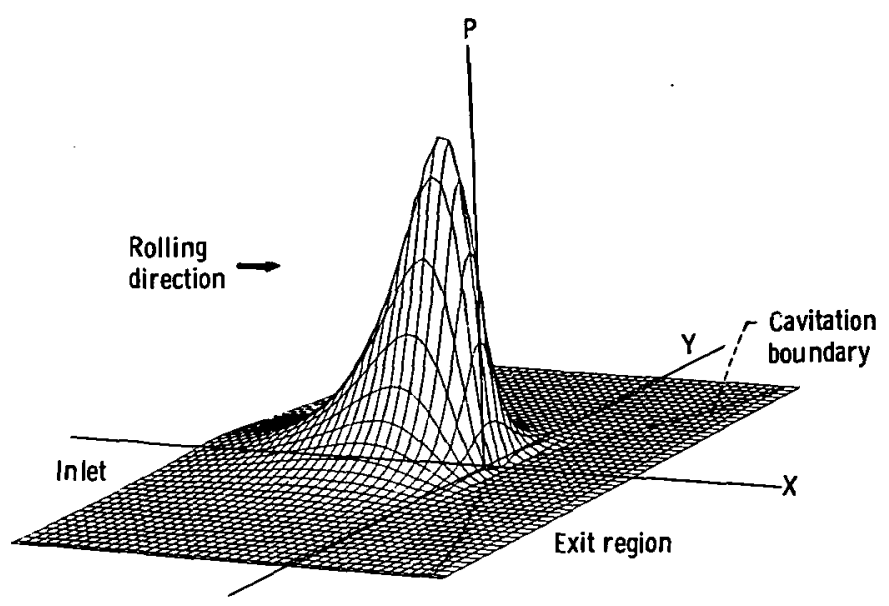

(a) Radius ratio, $a, 1.00$.

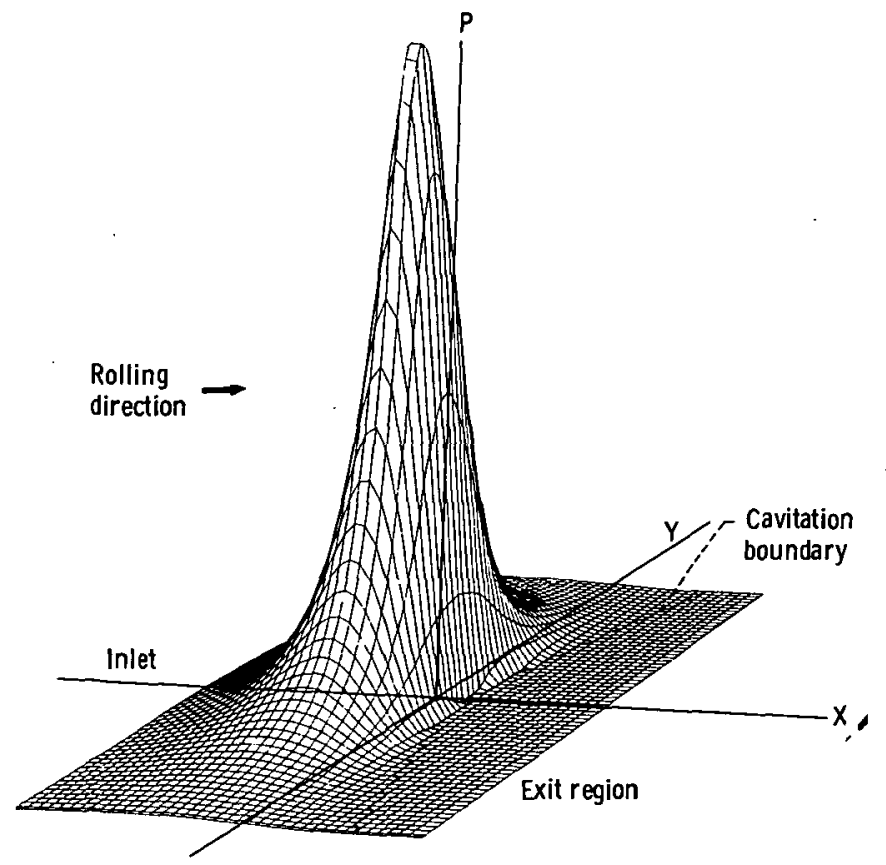

(D) Radius ratio, 0. 36.54.

Figure 6. - Three-dimensional representations of pressure distributions as viewed from exit region, illustrating cavitation boundary. 

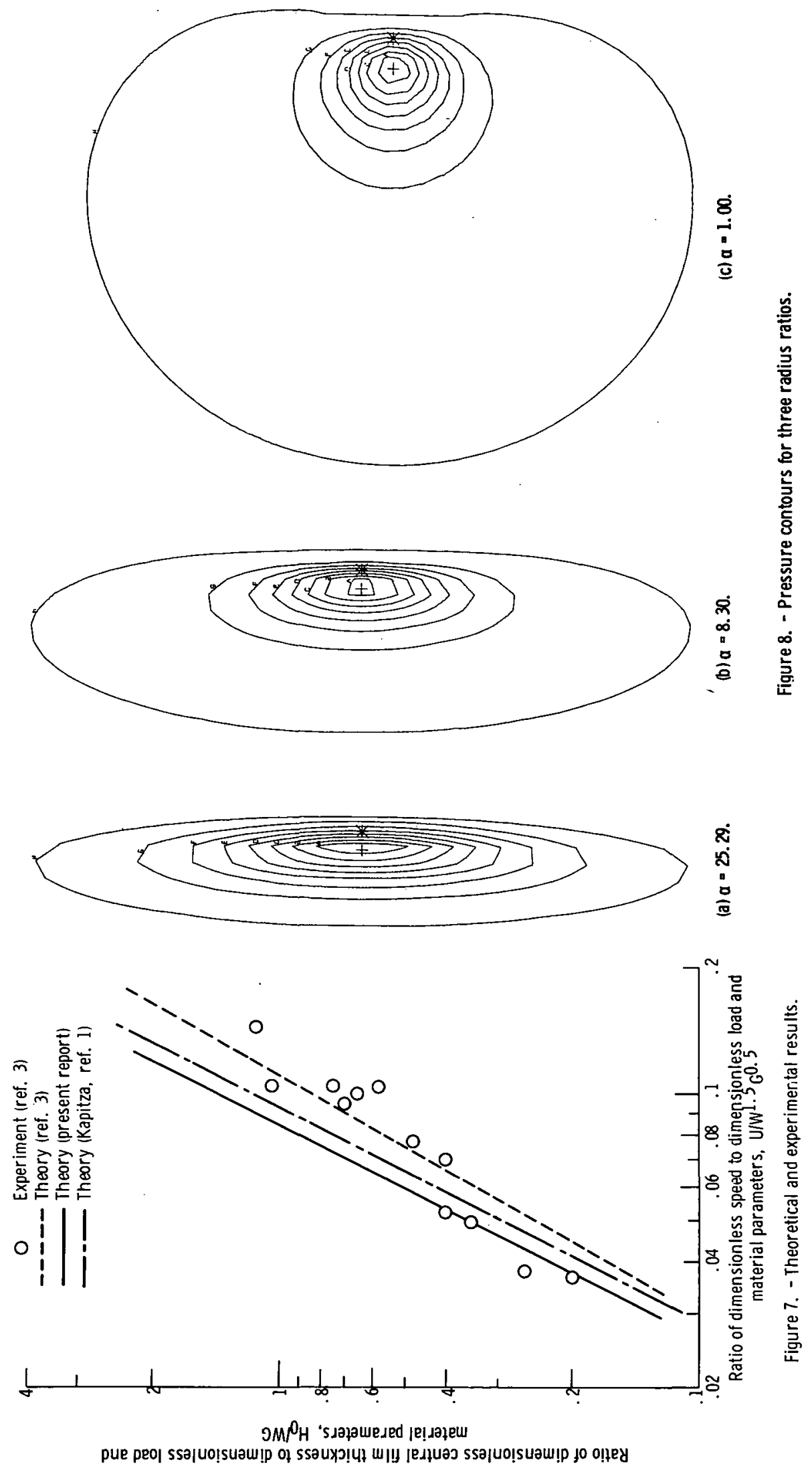


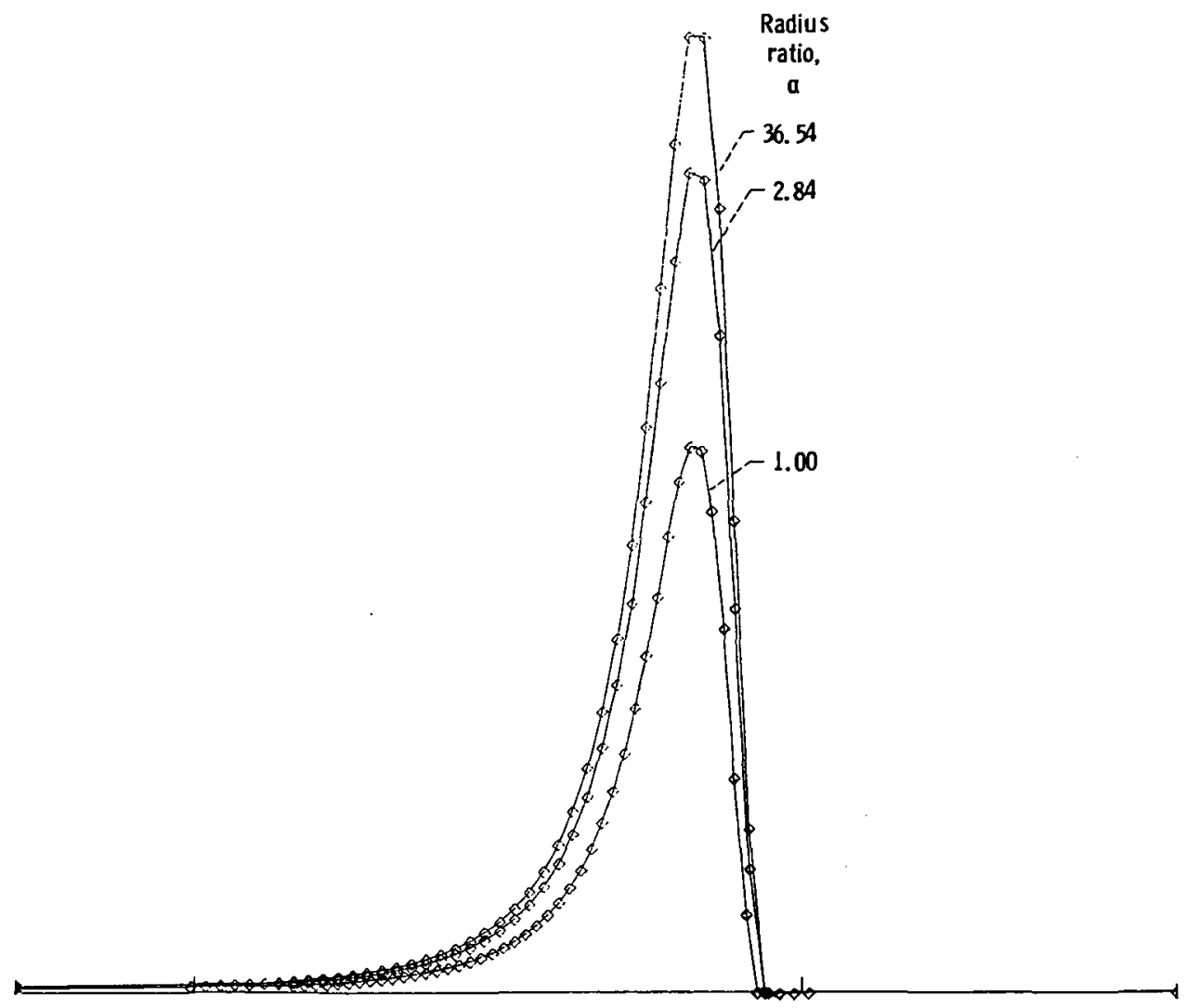

Figure 9. - Pressure profiles along rolling direction for dimensionless film thickness of $10^{-4}$ with three radius ratios. 


\begin{tabular}{|c|c|c|c|c|}
\hline $\begin{array}{l}\text { 1. Report No. NASA TP-1287 } \\
\text { AVRADCOM TR } 78-18(\mathrm{PL})\end{array}$ & \multicolumn{2}{|c|}{ 2. Government Accession No. } & \multicolumn{2}{|c|}{ 3. Recipient's Catalog No. } \\
\hline \multirow{2}{*}{\multicolumn{3}{|c|}{$\begin{array}{l}\text { 4. Title and Subtitle } \\
\text { EFFECT OF GEOMETRY ON HYDRODYNAMIC } \\
\text { FILM THICKNESS }\end{array}$}} & \multicolumn{2}{|l|}{$\begin{array}{l}\text { 5. Report Date } \\
\text { August } 1978\end{array}$} \\
\hline & & & \multicolumn{2}{|c|}{ 6. Performing Organization Code } \\
\hline \multicolumn{3}{|c|}{$\begin{array}{l}\text { 7. Author(s) } \\
\text { David E. Brewe, Bernard J. Hamrock, and } \\
\text { Christopher M. Taylor }\end{array}$} & \multicolumn{2}{|c|}{$\begin{array}{l}\text { 8. Performing Organization Report No. } \\
\text { E-9347 }\end{array}$} \\
\hline \multirow{2}{*}{\multicolumn{3}{|c|}{$\begin{array}{l}\text { 9. Performing Organization Name and Address } \\
\text { NASA Lewis Research Center and } \\
\text { AVRADCOM Research and Technology Laboratories } \\
\text { Cleveland, Ohio } 44135\end{array}$}} & \multicolumn{2}{|l|}{$\begin{array}{l}\text { 10. Work Unit No. } \\
505-04\end{array}$} \\
\hline & & & \multicolumn{2}{|c|}{ 11. Contract or Grant No. } \\
\hline \multirow{2}{*}{\multicolumn{3}{|c|}{$\begin{array}{l}\text { 12. Sponsoring Agency Name and Address } \\
\text { National Aeronautics and Space Administration } \\
\text { Washington, D.C. } 20546 \text { and U.S. Army Aviation Research and } \\
\text { Development Command, St. Louis, Mo. } 63166\end{array}$}} & \multicolumn{2}{|c|}{$\begin{array}{l}\text { 13. Type of Report and Period Covered } \\
\text { Technical Paper }\end{array}$} \\
\hline & & & \multicolumn{2}{|c|}{ 14. Sponsoring Agency Code } \\
\hline \multicolumn{5}{|c|}{$\begin{array}{l}\text { 15. Supplementary Notes } \\
\text { David E. Brewe, AVRADCOM Research and Technology Laboratories; Bernard J. Hamrock, } \\
\text { Lewis Research Center; Christopher M. Taylor, Lecturer in Mechanical Engineering, } \\
\text { University of Leeds, Leeds, England, National Research Council - NASA Research Associate. } \\
\text { Presentation at ASLE-ASME Joint Lubrication Conference, Minneapolis, Minn., Oct. 24-26, } 1978 .\end{array}$} \\
\hline \multicolumn{5}{|c|}{$\begin{array}{l}\text { 16. Abstract } \\
\text { The influence of geometry on the isothermal hydrodynamic film separating two rigid solids } \\
\text { was investigated. Pressure-viscosity effects were not considered. The minimum film } \\
\text { thickness is derived for fully flooded conjunctions by using the Reynolds boundary conditions. } \\
\text { It was found that the minimum film thickness had the same speed, viscosity, and load de- } \\
\text { pendence as Kapitza's classical solution. However, the incorporation of Reynolds boundary } \\
\text { conditions resulted in an additional geometry effect. Solutions using the parabolic film ap- } \\
\text { proximation are compared with those using the exact expression for the film in the analysis. } \\
\text { Contour plots are shown that indicate in detail the pressure developed between the solids. }\end{array}$} \\
\hline \multicolumn{2}{|c|}{$\begin{array}{l}\text { 17. Key Words (Suggested by Author }(s) \text { ) } \\
\text { Hydrodynamics; Film thickness; Bearings; } \\
\text { Lubrication; Isothermal processes; Rolling } \\
\text { contact loads; Sliding; Reynolds equation; } \\
\text { Leakage; Cavitation flow }\end{array}$} & \multicolumn{3}{|c|}{$\begin{array}{l}\text { 18. Distribution Statement } \\
\text { Unclassified - unlimited } \\
\text { STAR Category } 37\end{array}$} \\
\hline $\begin{array}{l}\text { 19. Security Classif. (of this report) } \\
\text { Unclassified }\end{array}$ & $\begin{array}{r}\text { 20. Security Clas } \\
\mathrm{U}\end{array}$ & $\begin{array}{l}\text { of this page) } \\
\text { assified }\end{array}$ & $\begin{array}{c}\text { 21. No. of Pages } \\
34\end{array}$ & $\begin{array}{r}\text { 22. Price } \\
\mathrm{A03}\end{array}$ \\
\hline
\end{tabular}

* For sale by the National Technical Information Service, Springfield, Virginia 22161 
National Aeronautics and

Space Administration

Washington, D.C.

20546

Official Business

Penalty for Private Use, $\$ 300$
Postage and Fees Paid

National Aeronautics and Space Administration

NASA-451

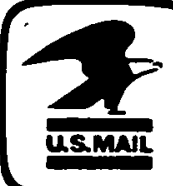

POSTMASTER:

If Undeliverable (Section 158 Postal Manual) Do Not Return 